\title{
Price and Earnings Momentum: An Explanation Using Return Decomposition
}

\author{
Qinghao Mao \\ Department of Finance \\ Hong Kong University of Science and Technology \\ Clear Water Bay, Kowloon, Hong Kong \\ Email:mikemqh@ust.hk \\ Tel: (852)-2358-7666 \\ Fax: (852)-2358-1749 \\ K.C. John Wei \\ Department of Finance \\ Hong Kong University of Science and Technology \\ Clear Water Bay, Kowloon, Hong Kong \\ Email: johnwei@ust.hk \\ Tel: (852)-2358-7676 \\ Fax: (852)-2358-1749
}

This version: 2010, September

\footnotetext{
*We appreciate helpful comments of Sudipto Dasgupta, Vidhan Goyal, Laura Liu, Long Chen, Michael Lemmon, seminar and workshop participants at the Hong Kong University of Science and Technology, the participants at China International Conference of Finance.
} 


\title{
Price and Earnings Momentum: An Explanation Using Return Decomposition
}

\begin{abstract}
We test rational and behavioral explanations for price and earnings momentum applying a unified framework using return decomposition. The results demonstrate that momentum profits do not come from the expected return component. Instead, momentum profits are mainly contributed by the positive cash flow return component and partially offset by the negative discount rate return component. The cash flow return component is quite persistent before and after portfolio formation. However, the dynamics in the discount rate return component explain why the ex-ante expected return does not account for momentum returns. In comparison with price momentum, earnings momentum does not rely on past discount rate news and does not display long term reversal. Overall, our empirical evidence based on return decomposition tends to support the behavioral explanation that the market incorporates cash flow information too slowly, which drives momentum returns.
\end{abstract}

JEL Classification: G11; G12; G14; M40

Key words: Return decomposition, Cash flow return component, Discount rate return component, Price momentum, Earnings momentum. 


\section{Introduction}

Extensive studies have documented the profitability of a trading strategy that buys recent past winners and simultaneously sells recent past losers, where winners are defined as those firms which have strong positive earnings surprises in the most recent quarter or stocks that have shown superior price performance in the past 3-12 months, and losers are defined as the opposite. The former is referred to as earnings momentum and the latter is referred to as price momentum. In addition, price momentum (as documented by Jegadeesh and Titman (1993)) and earnings momentum (as originally documented by Ball and Brown (1968) and later confirmed by Bernard and Thomas (1990) and others) are the two prominent anomalies that cannot be explained by Fama and French $(1992,1993)$ three-factor models. ${ }^{1}$

A number of explanations have been proposed to explain these two anomalies, including rational models and behavioral models. Behavioral explanations try to reconcile the anomalies with investor cognitive biases such as overconfidence and self-attribution bias (suggested by Daniel, Hirshleifer, and Subrahmanyam (DHS, 1998)) and investor initial underreaction to new information (proposed by Barberis, Shleifer, and Vishny (BSV, 1998) and Hong and Stein (1999)). ${ }^{2}$ Rational explanations, on the other hand, seek solutions based on either the serial correlation in the time-varying expected returns or cross-sectional differences in unconditional expected returns. To rationalize the positive serial correlation, Berk, Green, and Naik (1999) develop a model based on firms' optimal asset portfolio decisions, and Johnson (2002) introduces a growth rate shock that is episodically persistent. From a different perspective,

\footnotetext{
${ }^{1}$ The profitability of momentum strategies has been demonstrated in other markets outside the United States. See, for example, Rouwenhorst (1998) in Europe and Griffin, Ji, and Martin (2003) around the world. See Chui, Titman, and Wei (2010) for the determinants of the cross-country differences in momentum profits.

${ }^{2}$ The finding by Chui, Titman, and Wei (2010) that momentum profits are associated with individualism (a proxy for overconfidence and self-attribution bias) in their international study appears to be consistent with the prediction of the behavioral momentum model proposed by Daniel, Hirshleifer, and Subrahmanyam (1998).
} 
Conrad and Kaul (1998) find a nontrivial cross-sectional dispersion in mean returns and use this finding to justify the assertion that momentum profits are attributable to risk. ${ }^{3}$

Given the fact that realized returns can be decomposed into an expected return component and an unexpected return component, return decomposition provides a framework which may shed lights on distinguishing different explanations. There are two general ways, in the literature, designed to quantify price movement reasons in terms of cash flow news and discount rate news. The traditional approach is to decompose stock returns using a vector autoregression (VAR) method to model the discount rate news component, as suggested by Campbell and Shiller (1988) and Campbell (1991), and to use the residual from the return regression as a proxy for the cash flow news component. On the other hand, Chen and Zhao (2010) propose an alternative return decomposition method based on accounting valuation models and analyst earnings forecasts. The new approach has certain advantages in that it circumvents the model misspecification and the predictability issues inherited by the traditional approach. They find empirical evidence that justifies the utility of this new method in identifying underlying forces that drive the time-series stock price movements on both firm level and the aggregate level. ${ }^{4}$

This study extends Chen and Zhao's (2010) return decomposition method to investigate momentum anomalies in cross sectional stock returns. Specifically, we attribute the profitability of momentum strategies to the contributions from each of the three components: the expected return component, the cash flow return component, and the discount rate return component. These three return components are defined so as to capture stock price movements driven by

\footnotetext{
${ }^{3}$ However, Jegadeesh and Titman (2002) argue that the findings of Conrad and Kaul are subject to small sample biases and that differences in cross-sectional expected return, in fact, contribute very little to momentum profits.

${ }^{4}$ The traditional wisdom is that cash flow news dominates at the firm level, while discount rate news dominates at the aggregate level in driving price movements. However, Chen and Zhao (2010) document that the importance of cash flow news far exceeds that of discount rate news at both the firm and aggregate levels when the time horizon is longer than three years. Discount rate news dominates in short horizons.
} 
compensation for risk, changes in expected earnings prospects, and changes in investor risk perceptions, respectively. The expected return component, a measure related to the implied cost of equity, is a proxy for ex-ante expected compensation for risk. ${ }^{5}$ The cash flow return component captures analyst revisions in earnings forecasts. A positive cash flow return component reflects an upward revision in analyst earnings forecasts. The discount rate return component reflects the risk-adjustment effect that incorporates both investor time-varying risk aversion/sentiment and market risk premium. The underlying dynamic is that a decrease in investor risk aversion and/or market risk premium is associated with a decrease in the discount rate, which, in turn, generates a positive discount rate return, and vice versa. In other words, a decrease in risk causes the current stock price to go up (i.e., a positive return) and the expected future return (or the discount rate) to go down. The direct intuition using return decomposition in analyzing momentum strategies profitability is that: if the expected return component dominates, risk-based models are more plausible; if the unexpected or innovation components dominate, behavioral justifications might be more appropriate. When investors behave rationally and the market is efficient, on average we should not expect systematic positive or negative return innovations within stock categories.

The return decomposition method also expands the dimension where we may infer the differences in price momentum and earnings momentum. Chan, Jegadeesh, and Lakonishok (1996) document that past returns and past earnings surprises contain orthogonal information that predicts the drifts in future returns. Chordia and Shivakumar (2006) focus on the systematic components in price momentum and earnings momentum. They find that price momentum can be explained using the factor regressions where an earnings momentum factor is included. In contrast, controlling a price momentum factor does not help explain earnings momentum. They

\footnotetext{
${ }^{5} \mathrm{Wu}$ and Zhang (2010) also test different cross-sectional anomalies using a similar ex-ante expected return measure.
} 
therefore claim earnings momentum subsumes price momentum. Our study is designed to examine the functions of different return components in distinguishing between these two related momentum anomalies. We aim to explore whether or not the two anomalies differ in terms of return components in both the formation period and the holding period. Since cash flow news dominates discount rate news in explaining stock price movements over long horizons (Chen and Zhao (2010)), the relative contributions of the cash flow return component and the discount rate return component might provide useful implications on the long-run performance of the two momentum strategies.

Our empirical tests show that momentum anomalies are not driven by the expected return component. Instead, it is a persistently positive cash flow return component that drives both price momentum and earnings momentum. A negative discount rate return component partially offsets post-formation returns for both anomalies, but it contributes to pre-formation returns only of price momentum but not of earnings momentum. Thus, on the one hand, our results tend to confirm a behavioral explanation that the market incorporates cash flow news too slowly and investors behaves like price anchoring. The risk measure based on ex-ante implied cost of equity capital fails to account for the ex-post price performance of momentum strategies. On the other hand, the comparison of the two momentum strategies implies that the portfolio selection criteria could induce differences in their long run performances. Price momentum strategy based on sorting period both cash flow and discount rate information only picks temporary winners. In contrast, permanent winners seem to be screened out by earnings momentum strategy that relies on recent cash flow information only.

Overall, our paper contributes to the momentum and return decomposition literatures by applying a unified framework to distinguish between risk-based and behavioral explanations for 
price momentum and earnings momentum. The expected return reflects the market compensation for risk, while the return innovations reflect the market behavior in incorporating new information. Motivated by the ex-ante expected return measures in Wu and Zhang (2010), we regard our study as among the earliest that offer additional evidence through quantifying the role of return innovations and also exploring the time-series dynamics of the ex-ante return measure in momentum returns. ${ }^{6}$ Campbell and Vuolteenaho (2004) use cash flow betas and discount rate betas to explain the size and value anomalies in stock returns. ${ }^{7}$ Instead of relying on co-variations with systematic components to explain the cross-sectional differences in stock returns, the magnitude of the idiosyncratic contributions from return innovations is measured directly in this study. Our paper also complements the literature that uses the implied cost of equity from accounting valuation models to examine the issues such as the default risk, voluntary disclosure, and corporate governance. For momentum anomalies, we show that the risk-based explanation using the implied cost of equity is counterintuitive, and the importance of return innovations should not be overlooked.

The rest of the paper proceeds as follows. In Section 2, we describe our return decomposition methodology. Section 3 develops the hypotheses based on rational and behavioral models. In Section 4, we test the cross-sectional and time-series dynamics of each of the three return components in price momentum and earnings momentum. We then explore the long-term performance of these two momentum strategies. Section 5 discusses robustness checks. Finally, Section 6 concludes the paper.

\footnotetext{
${ }^{6} \mathrm{Wu}$ and Zhang (2010) use dividend discounting models to directly estimate ex-ante expected returns for their test portfolios and use one residual income model to indirectly estimate portfolios' expected returns through individual stock's expected returns. Different from their method, we decompose stock returns at the individual stock level using the median estimates from four residual income models.

${ }^{7}$ They associate the high returns of small stocks and value stocks to the high cash flow betas, which is consistent with the inter-temporal asset-pricing theory that high cash flow betas bear high risk premiums. Da and Warachka (2009) links systematic risk from earnings revisions to the cross-section of stock returns.
} 


\section{Return Decomposition}

We extend the method used by Chen and Zhao $(2009 ; 2010)$ by decomposing realized stock returns into three components. More specifically, monthly stock returns are decomposed into an expected return component and an unexpected return component, and the latter is further decomposed into a return component due to cash flow innovations and another return component due to discount rate innovations. In a valuation model, a stock price $\left(P_{t}\right)$ can be expressed by a functional form $(f)$ of forecast future earnings at time $t\left(c f_{t}\right)$, the discount rate at time $t\left(d r_{t}\right)$, and time $(t)$. Therefore, the realized stock return $\left(R_{t}\right)$ from $t-1$ to $t$ can be expressed as follows ${ }^{8}$ :

$$
R_{t}=\frac{P_{t}-P_{t-1}}{P_{t-1}}=\frac{f\left(c f_{t}, d r_{t}, t\right)-f\left(c f_{t-1}, d r_{t-1}, t-1\right)}{P_{t-1}}
$$

In different form,

$$
R_{t}=\frac{\frac{\partial f_{t}}{\partial c f} \times \Delta c f}{P_{t-1}}+\frac{\frac{\partial f_{t}}{\partial d r} \times \Delta d r}{P_{t-1}}+\frac{\frac{\partial f_{t}}{\partial t} \times \Delta t}{P_{t-1}}=\text { CFret }_{t}+\text { DRret }_{t}+\text { Eret }_{t}
$$

where CFret, DRret, and Eret are defined as follows:

$$
\begin{aligned}
& \text { CFret }=\frac{\frac{1}{2}\left[f\left(c f_{t}, d r_{t}, t\right)-f\left(c f_{t-1}, d r_{t}, t\right)+f\left(c f_{t}, d r_{t-1}, t\right)-f\left(c f_{t-1}, d r_{t-1}, t\right)\right]}{P_{t-1}}, \\
& \text { DRret }=\frac{\frac{1}{2}\left[f\left(c f_{t}, d r_{t}, t\right)-f\left(c f_{t}, d r_{t-1}, t\right)+f\left(c f_{t-1}, d r_{t}, t\right)-f\left(c f_{t-1}, d r_{t-1}, t\right)\right]}{P_{t-1}}, \text { and } \\
& \text { Eret }=\frac{f\left(c f_{t-1}, d r_{t-1}, t\right)-f\left(c f_{t-1}, d r_{t-1}, t-1\right)}{P_{t-1}}
\end{aligned}
$$

\footnotetext{
${ }^{8}$ We add dividends, if any, back to $P_{t}$ in the decomposition so that the total return equals to the capital gain and the dividends. The prices include the dividend value distributed from $t-1$ to $t$.
} 
Eret is the discount rate estimated from a residual income model using cash flow forecasts and stock price at time $t$-1. Eret is known ex-ante and is the return that investors expect at time $t-1$ assuming no cash flow or discount rate shocks between $t$ - 1 and $t$. Eret represents the composition of market time value of money and stock specific risk premium. CFret is the return component due to changes in forecast cash flows holding both the discount rate and time constant. A positive CFret is a result of an upward revision in earnings forecasts, since $\frac{\partial f_{t}}{\partial c f}$ is positive. DRret is the return component due to changes in the discount rate holding both forecast cash flows and time constant. A positive DRret is a result of a downward revision in the discount rate. Intuitively, stock prices can rise in addition to the part that is justified by the compensation for risk due to either good news about firm future earnings prospects or downward adjustment in discount rates which may come from lower investor risk aversion and higher sentiment. In practice, corporate specific or market information can signal both cash flow news and discount rate news simultaneously. The return decomposition thus attempts to separately quantify their contributions so as to identify the sources of profitability in the context of momentum strategies. The results should have economic implications similar to those of the VAR approach suggested by Campbell and Shiller (1988). ${ }^{9}$

Equations (1) and (2) are equivalent. If residual income models are a good proxy for stock valuation and the market is efficient, if there are no cash flow shocks and no changes in investor perceptions of discount rates, the return spread between two single stocks or two groups of

\footnotetext{
${ }^{9}$ But it is slightly different from the one suggested by Lo and MacKinlay (1990). Lo and MacKinlay (1990) also decompose momentum or contrarian returns into three components: cross-sectional difference in returns, autocorrelations, and cross-correlations. The cross-sectional difference in returns is similar to our expected component of returns (Eret). One of the advantages of our decomposition method is that our method can apply to any individual stock or any portfolio, while the decomposition method suggested by Lo and MacKinlay can only apply to a very specific momentum or contrarian portfolio that uses a weighted relative strength strategy.
} 
stocks should be on average equal to the spread in their expected return component. Since both cash flow returns and discount rate returns are unpredictable in efficient market, some stocks will have positive return shocks and others have negative return shocks. On average, as more stocks are included in the portfolio and as more observations in the time series are included, there should be no systematic differences in cash flow returns and discount rate returns across stock categories. Note that a test based on the return components is a joint hypothesis. A rejection of the predictions by the rational explanation can be due to either the inadequacy of residual income models or the market's being inefficient. The predictions of the rational and behavioral models on the profits of momentum strategies will be discussed in the next section.

As in previous work in this field, analysts' earnings forecasts are used as a proxy for market expectations when applying the residual income models. Givoly and Lakonishok (1980) and Stickel (1991) show that stock markets do favorably react to upward revisions in analyst earnings forecasts, which suggests that revisions in analyst earnings forecasts help price discovery. Therefore, residual income models are useful, at least, in describing changes in firm valuation. In addition, Pástor, Sinha, and Swaminathan (2008) show analytically that under plausible conditions, the implied cost of equity is perfectly correlated with conditional expected stock returns. In an empirical analysis, they construct the time-series implied cost of capital for G-7 countries and find a positive relation between the implied cost of capital and the variance of stock returns, both by country and on a world market level. These results suggest that residual income models usefully estimate firm value, and especially changes in firm value.

We calculate the implied cost of equity or the expected return for each firm over a monthly horizon using accounting valuation models. Four valuation models from the accounting literature, those of Gebhardt, Lee, and Swaminathan (2001), Claus and Thomas (2001), Ohlson and 
Juettner-Nauroth (2005) and the Modified PEG ratio model by Easton (2004) are applied. The details are discussed in Appendix 1. Since there is little consensus in the literature about which model is preferable, we follow Hail and Leuz (2006), Chen, Chen, and Wei (2010) and others in using the median estimate from the four models to mitigate the effect of measurement errors. With the implied cost of equity capital estimated from the corresponding valuation model, we then calculate the three return components using equations (3), (4) and (5).

The return decomposition method based on analyst forecasts to proxy for cash flow news has some advantages over the traditional VAR approach, since the VAR estimation is sensitive to which state variables are chosen and subject to model misspecification problems (Chen and Zhao (2009)). The method we use does not rely on the predictability of the chosen macroeconomic variables in the VAR model, and it can facilitate understanding the time-series characteristics of individual stock price movements with similar pricing approaches widely used in practice. Since we use consensus analyst earnings forecasts to proxy for market expectations, the discount rate return component will capture all residual news that cannot be explained by any revisions in earnings forecasts and by compensation for risk. In the extreme case where the analyst earnings forecasts contain little information about the marginal investor expectations about firm earnings, the same pattern/distribution in the total realized return should be fully reflected in the discount rate return and the implied cost of equity (i.e., the expected return). Thus, any findings based on the cash flow return pattern are not a mechanical coincidence. ${ }^{10}$ In the model, the expected return component represents risk. For example, for two firms with the same future earnings forecasts and also the same long-term growth rate forecasts, the one with a higher current stock price

\footnotetext{
${ }^{10}$ In the context of exploring the role of cash flow news in driving stock returns, Chen and Zhao (2010) argue that their estimates of the importance of cash flow news using analysts' earnings forecasts should be regarded as a lower bound.
} 
should have relatively lower discount rate associated with its equity, and it follows that the corresponding expected return will also be lower.

The present value formula in the return decomposition uses a constant discount rate for each stock at a given time. This assumption simplifies the return decomposition such that the estimated cash flow return component and the discount rate return component can capture the cash flow news and discount rate news, respectively. Analytically the price of a stock can always be represented by discounted future cash flows using a constant equivalent discount rate. Overall, we will interpret the results in the conditional sense and recognize that there are other ways of return decomposition and various valuation structures in practice. Our approach based on the four accounting valuation models and also in line with current studies in the literature can be regarded as a simple benchmark that quantifies cash flow and discount rate contributions to the price movements.

\section{The Momentum Portfolios and Hypotheses Development}

We follow Jegadeesh and Titman (1993) and Chordia and Shivakumar (2006). in constructing price momentum and earnings momentum portfolios. Specifically, using the sample based on return decomposition, each month we sort all stocks into deciles based on their cumulative returns over the past six months. A price momentum strategy involves a long position in the best past performers (D10) and a short position in the worst past performers (D1). For earnings momentum, each month, we sort all stocks in the sample into deciles based on their most recent past standardized earnings surprise (SUE). SUE is defined as follows:

$$
S U E_{i t}=\frac{e_{i q}-e_{i q-4}}{\sigma_{i t}}
$$


where $e_{i q}$ is the most recent quarterly earnings per share as of month $t$ for stock $i, e_{i q-4}$ is earnings per share four quarters ago, and $\sigma_{i t}$ is the volatility of $e_{i q}-e_{i q-4}$ over the prior eight quarters. Similarly, an earnings momentum hedge portfolio is composed of a long position in D10 and a short position in D1. We term D10 the winner group and D1 the loser group in both price momentum and earnings momentum cases. The portfolios are held for six months after formation and the stocks are equally weighted within each portfolio every month.

Inspired by the consistently profitable momentum strategy documented in empirical studies since Jegadeesh and Titman (1993), many studies have arisen to provide theories on what's behind the outperformance of the winner group over the loser group in the subsequent three months to one year. The study by Conrad and Kaul (1998) rationalizes momentum profits by attributing the strategy profits to the cross-sectional dispersion in expected returns across portfolios, which, in turn, are determined by risk. In the return decomposition framework, it would imply that the expected return component (Eret) is positive for the hedge portfolio during both the pre-formation and the post-formation periods and that the other two unexpected return components do not have systematic effect on momentum profits. Instead of arguing a persistent higher risk for winners as compared to losers, Johnson (2002) pins down the time series variation in the expected returns by modeling that momentum sorts tend to sort firms in a way reflecting recent growth rate shocks, which makes the winner group riskier and thus will outperform the loser group in subsequent months. Mapped to our framework, the time series variation in risk would suggest a negative discount rate return component (DRret) for the hedge portfolio during the pre-formation period which implies the increase in risk and subsequent positive expected returns. Besides, positive recent growth rate shocks are represented by a positive cash flow return component (CFret) pre-formation. Since both arguments underline the importance of the 
expected returns in driving holding period momentum profits, they represent two rational interpretations.

Hypothesis 1: As implied by the rational momentum model of Conrad and Kaul (1998), the expected return component of a momentum portfolio is positive and both its cash flow and discount rate return component are zero during both the pre-formation and post-formation periods.

Hypothesis 2: As implied by the rational momentum model of Johnson (2002), the expected return component of a momentum portfolio is positive during the post-formation period. In addition, the cash flow return component is positive, while the discount rate return component is negative during the pre-formation period.

Behavioral explanations, however, shed more lights on the return innovations in spreading return patterns in the cross section. Theoretical works usually suggest investor underreaction (BSV (1998)) or overconfidence with self attribution biases (DHS (1998)) as the main reason for momentum stock returns. In other words, the majority of the post-formation momentum profits should come from return innovations, i.e., the cash flow return component or/and the discount rate return component. For example, growing confidence about firm future earnings would result in persistent inflation of firm earnings expectations. Also, increasing risk aversion and pessimistic opinions about macroeconomic environment (for example, during market crash) would manifest increasing discount rates applied by marginal investors. In addition, behavioral momentum models do not make any prediction about the cross-sectional dispersion in expected returns or risk between the winner group and the loser group. The bottom line is return innovations outweigh the expected return component in forming stylized return patterns. 
Hypothesis 3: Implied by the behavioral momentum models of DHS (1998), BSV (1998), and Hong and Stein (1999), the cash flow return component of a momentum portfolio is positive during the post-formation period. In addition, the sum of the cash flow and discount rate return components is positive.

Empirical justification of the above hypotheses, of course, does not eliminate the possibility of discovering crucial affects by both the expected return component and the components of return innovations. In that case, a mixed explanation with partially rational and partially behavioral insights might be appropriate. Still, return decomposition quantifies how much of each return component contributes to the return distribution so that it can facilitate our understanding of the relative importance of rational versus behavioral forces in driving momentum stock returns.

\section{Empirical Tests}

This section first describes the dataset we use for return decomposition and reports summary statistics of return components. CFret, DRret, Eret are compared across price momentum and earnings momentum portfolios to show their relative importance in delivering patterns in cross sectional total returns. To explore the time series dynamics, we than illustrate the portfolio performances in months before and after portfolio formation. Next we present price and earnings momentum strategy performances in long horizons and their relations with each return component. Finally, the calendar time properties of momentum profits are discussed.

\subsection{Return Components}

We extract analysts' monthly earnings forecasts from the Institutional Brokers' Estimate System (I/B/E/S) historical file including one to three years ahead forecast earnings per share and 
long-term growth rate forecasts. Annual accounting variables and monthly stock returns are from Compustat and CRSP databases. The sample period is from 1985 to $2008^{11}$. Following the kind of previous studies, all financial firms are excluded from the sample. I/B/E/S monthly median forecasts are then matched to Compustat financial statement variables by aligning earnings forecasts to be one to three years ahead of the current accounting variables' fiscal year end. The data are merged with monthly stock returns by synchronizing the time of the earnings forecasts with that of the stock returns. This process results in a sample of 680,389 firm-month observations.

Using the four accounting valuation models discussed previously, the return decomposition method generates estimates of the implied cost of equity, the expected return component, the cash flow return component and the discount rate return component. Mechanically, the three return components add up to the total realized return. We delete observations with an estimated annual implied cost of equity either above 0.8 or below zero. We then take the median implied cost of equity estimated from the four valuation specifications where possible, as the final cost of equity estimate, and use the corresponding three return components in the momentum tests. This screening process results in a final sample of 449,175 firm-month observations. ${ }^{12}$

Panel A of Table 1 reports the average number of firms each year. On average, there are about 1,687 firms each year with valid decomposed return components. Panel B of Table 1 presents the correlation matrix relating the estimated cash flow return and discount rate return components from each of the four valuation models and the estimates based on the median cost

\footnotetext{
${ }^{11}$ Most analyst forecasts data (I/B/E/S) are unavailable before 1985 . We stop at 2008 so as to exclude the recent financial crises period during which the momentum strategy, in sharp difference to usual cases, generates big negative returns.

${ }^{12}$ This is about one quarter of the number of observations in the CRSP monthly stock returns file during the same time period due to the availability of earnings forecasts.
} 
of equity estimates (from the four valuation models). Correlations between CFret and cash flow return components of individual valuation models (GLS, CT, ROJ, MPEG) are above 50\%. Correlations between DRret and discount rate return components of the four models are above 70\%. Given each model has distinct assumption about the valuation structure, the high correlation coefficients indicate that there are big commonalities in the function of quantifying cash flow news and discount rate news in stock returns.

\section{[Insert Table 1 here]}

Panel C of Table 1 reports the summary statistics of CFret, DRret, Eret and Ret. Panel D shows their inter-correlations. The concentrated distribution (Mean $=0.009$ and Std $\mathrm{dev}=0.003$ ) of the monthly Eret suggests that the expected return component is quite persistent over time. The mean of CFret and DRret are $-0.8 \%{ }^{13}$ and $1.1 \%$ per month. As expected, DRret, which captures all residual news, is highly correlated with the total return with a correlation coefficient of 0.569. The highly negative correlation (-0.756) between DRret and CFret indicates that positive cash flow news is generally accompanied by negative discount rate news. That is, the decomposition using residual income models suggests that good news about expected earnings is associated with bad news about discount rates (i.e., increases in risk). From the perspective of a firm, we could think of it expanding growth opportunities and taking on higher risk. On the investor side, it could mean that people are still conservative about the firm value though they revise upward the future earnings expectations.

\subsection{Momentum profits and return components}

Panel A of Table 2 reports the profits of the price momentum portfolios and the relative contributions from cash flow returns, discount rate returns, and expected returns. Consistent with

\footnotetext{
${ }^{13}$ Previous studies document that analyst forecasts tend to be too optimistic which accounts for why in monthly horizons there are more downward revisions than upward revisions.
} 
the findings of previous research, portfolio returns for a price momentum strategy increase almost monotonically from the loser group to the winner group with a return spread of $0.85 \%$ per month. This is less than the $1 \%$ monthly return spread documented by previous studies due to the sample screening criteria that only relatively large stocks having analysts' earnings forecasts are included. ${ }^{14}$ Since Chan et al. (1996) and others have already documented a positive correlation between returns and revisions in analysts' forecasts for price momentum portfolios, the monotonically increasing pattern in the cash flow return component is no surprise.

The magnitude of the monthly return spread (4.90\%) in the cash flow return component is much larger than the spread in the total momentum return. The quantitative implication based on the cash flow return component is that momentum profits are five times larger if there is no change in the discount rate. ${ }^{15}$ An opposite pattern is observed in the discount rate return component. Basically, discount rate returns work in a way that partially offsets the spread driven by cash flow returns with a magnitude of about $-3.90 \%$ per month, or about $80 \%$ of the cash flow return spread. The spread in the expected return component between winners and losers is negative (-0.15\%), and quantitatively very small as compared to either the cash flow return component or the discount rate return component. The results thus tend to support hypothesis $\mathbf{3}$ that highly positive CFret partially offset by the negative DRret causes the winner group to outperform the loser group. The dominance of CFret leads to the profitability of price momentum strategy.

[Insert Table 2 here]

\footnotetext{
${ }^{14}$ Jegadeesh and Titman $(1993,2001)$ and others document the fact that momentum profits are greater among small stocks than large stocks.

${ }^{15}$ We do not propose new trading strategies based on sorting using either the cash flow return component or the discount rate return component. Our objective is to provide explanations on the profitability of the existent momentum strategies. Further, the two return components are highly correlated and difficult to separate.
} 
The magnitude of the expected return spread ( $\Delta E$ Eret) is quite small as a fraction of the total price momentum profit and it even contributes negatively to the momentum profits. So at least we cannot find supporting evidences for either hypothesis $\mathbf{1}$ or hypothesis $2 .{ }^{16}$ It may explain why researchers find it difficult to discover empirical evidence that can reconcile momentum profits with rational or risk explanations (see, for example, Chui, Titman, and Wei (2010)).

Panel B of Table 2 reports results for earnings momentum. Generally, the return patterns are similar to those for price momentum. The realized return spread between D10 and D1 is $4.23 \%$, smaller than that for price momentum, consistent with the previous findings in Chordia and Shivakumar (2006). The cash flow return component dominates the other return components. The cross-sectional spread between winners and losers is $1.77 \%$ per month for the cash flow return component, while the discount rate return component partially offsets the spread by $1.27 \%$ per month. Similarly, the expected return component (a spread of $-0.08 \%$ per month between winners and losers) fails to deliver evidences supporting hypothesis $\mathbf{1}$ and hypothesis $\mathbf{2}$.

\subsection{Return dynamics before and after portfolio formation: Price momentum}

To provide a closer look at how different return components evolve over time and to highlight the dynamics of return components around portfolio formation, Table 3 reports the month-by-month decomposed return components for the price momentum portfolios from six months before to six months after portfolio formation. The time-series variations in the return components are plotted in Figure 1.

\section{[Insert Table 3 and Figure 1 here]}

The time-series dynamics of price momentum profits (as shown in the top panel of Figure 1), the loser profits (in the middle panel), and the winner profits (in the bottom panel) demonstrate

\footnotetext{
${ }^{16}$ The result is consistent with the finding by Wu and Zhang (2010) that the momentum anomaly does not exist $e x$ ante using implied expected returns based on residual income models.
} 
that the discount rate return component (DRret) basically reproduces the time-series dynamics of the realized returns for these three portfolios. The evidence from these momentum-related portfolios supports the claim by Chen and Zhao (2010) that discount rate news drives the timeseries return variation in the short time horizon at both the firm and aggregate levels. In the current momentum strategy context, Figure 1 shows that the time-series variations in returns are driven by the discount rate component, while the significantly positive cross-sectional return spread between winners and losers is driven by the net effect of the cash flow return component and the discount rate return component. Since at a monthly horizon, most of the cash flow news is firm specific, this underlines the fact that stock specific components are important in explaining momentum profits (Grundy and Martin (2001)).

It is also interesting to compare the profits of the three portfolios (winner, loser, and winnerminus-loser portfolios) in the pre-formation sorting period with those in the post-formation holding period. The results in Table 3 and Figure 1 show that the pre-formation profits and postformation profits of the price momentum strategy are significantly different. Specifically, the winner portfolio experiences price increases due to better earnings expectations and decreases in discount rate in the pre-formation period. In the same period the loser portfolio experiences price decreases due to deteriorating earnings prospects and increases in discount rates. As a result, both cash flow returns and discount rate returns contribute positively to the winner portfolio and negatively to the loser portfolio, which suggests that the two unexpected return components cooperatively contribute to the profits of momentum portfolio in the sorting period. In contrast, entering to the holding period, the discount rate returns display reversal and the cash flow returns display continuation. Post-formation momentum profits are a net result of positive cash flow returns and negative discount rate returns. Overall, the persistence of cash flow news extends the 
rewards to the momentum strategy into the post-formation period, while the reversal in discount rate news causes the magnitude of the hedge portfolio returns to be much smaller in the holding period than in the sorting period.

The discount rate return models the effect due to change in discount rate or risk. The reversal pattern then directly has implications on the dynamics of risk embedded in the momentum portfolio. It means that the risk of the price momentum portfolio decreases gradually before portfolio formation and gradually rises in the holding period. As a result, at the time of portfolio formation, the winner portfolio actually appears to be less risky than the loser portfolio, which to some extent solves the puzzle why ex-ante expected returns cannot account for momentum profits.

\subsection{Return dynamics before and after portfolio formation: Earnings momentum}

The time-series dynamics for earnings momentum profits are shown in Table 4 and Figure 2. The patterns are similar to those for price momentum with some varieties. To illustrate, first, the time-series variations in price movements are also dominated by the discount rate return component. Next, cash flow news shows a continuation pattern. The pre-formation earnings momentum profit is only about $4 \%$ per month, which is substantially smaller than the price momentum of around $16 \%$ per month. This could be easily understood as the contribution by the discount rate component to the pre-formation earnings momentum profit is very small and not significant. In addition, the CFret curve in the D10-D1 graph for price momentum is inverse Ushaped, while the corresponding curve for earnings momentum shows a monotonically decreasing trend. It seems that price momentum strategies tend to select the winner portfolio for which the comprehensive cash flow innovations are the highest at the time of portfolio formation, while earnings momentum strategies screen out the winner portfolio for which the peak of 
comprehensive cash flow innovation occurs in the past. As persistence in the cash flow return component is the main driver for post-formation momentum profits, price momentum strategies produce higher profits than earnings momentum strategies.

[Insert Table 4 and Figure 2 here]

Overall, the time-series result shows that the expected return component plays no role in driving either price or earnings momentum profits. Rather, the persistence in momentum profits during the six-month post-formation period is driven by the persistence in the cash flow return component. The momentum profits are a net effect of positive cash flow news and negative discount rate news. From behavioral models, the results imply that the market incorporates cash flow news slowly, which leads to the persistence in momentum profits. As investors gradually revise their expectations of firm earnings prospects, past winners (or high SUE stocks) continue to outperform past losers (or low SUE stocks). The return innovations dominate the expected return component, suggesting that risk cannot explain momentum profits. On the other hand, the reversal in the contribution of the discount rate return component causes the observed momentum profits to be much smaller in the post-formation period than in the pre-formation period. The evidence of a downward adjustment in risk during the pre-formation period and an upward adjustment in risk during the post-formation period again contradicts the risk-based explanations for the profitability of momentum strategies.

\subsection{The characteristics of price and earnings momentum portfolios}

Table 5 reports the characteristics of the momentum portfolios before the holding period. Panel A shows the characteristics of the price momentum portfolios. Sorting on past six-month returns tend to sort on both the past CFret component and the past DRret component, with 6.4\% and $11.0 \%$ contribution from each to the spread between D10 and D1. About half of the 
portfolios (Portfolios 1 to 7 ) on average experience negative cash flow news, and the rest experience positive cash flow news in the six-month pre-formation period. Just before the holding period, the implied cost of equity capital is negatively correlated with past price performance. The winner portfolio seems to lower discount rate. If there are no systematic differences in return innovations between winners and losers in the holding period, the momentum strategy is expected to lose money or at least be unprofitable. It follows that ex-ante expected returns cannot explain the price momentum profits. No significant inference can be drawn in terms of the long term earnings growth rate forecasts. The most recent past SUE monotonically increases across price momentum portfolios with a spread of 2.0 , in line with the common notion that past winners tend to experience greater earnings surprises.

\section{[Insert Table 5 here]}

Panel B of Table 5 shows the characteristics of the earnings momentum portfolios. The mean past six-month CFret spread between the two extreme earnings momentum portfolios is $3.9 \%$, which is about half of the spread in price momentum case. The mean past six-month DRret spread between the two extreme earnings momentum portfolios is very small $(0.1 \%)$. The difference in the implied cost of equity capital between two extreme earnings momentum portfolios at the time of portfolio formation is tiny (annualized $-1.4 \%$ ). The discount rate is 11.5\% for Decile 1 and $10.0 \%$ for Decile 10. However, the long term earnings growth rate forecast suggests higher expected growth rates associated with higher SUE portfolios. The sorting variable SUE naturally shows a large dispersion across deciles.

The differences between price and earnings momentum portfolios in terms of different dispersions in past CFret, DRret, and Eret may account for their different ex-post return behavior. Our return decomposition method appears to offer additional evidence that confirms the claim of 
Chan, Jegadeesh and Lakonishok. (1996) that past returns and past earnings surprises contain orthogonal information and both can predict future returns.

\subsection{Long run profitability}

In order to understand why price momentum profits start to reverse starting from 12 months after portfolio formation as documented in previous empirical studies, Table 6 presents the momentum profits over different holding horizons.

\section{[Insert Table 6 here]}

Table 6 shows that price momentum strategies earn significant positive returns only during the first six months. For the next six months, price momentum profits are still positive but less significant statistically and economically. After one year, price momentum profits are either significantly negative (Months 13-18 and 25-36) or insignificant (Months 19-24). In addition, the negative returns in later years completely eliminate the profits generated from the first 12 months (easily inferred from the table). These patterns support the findings of Jegadeesh and Titman (2001) who report that the profitability of price momentum portfolios over longer holding horizons can be predicted with behavioral models. ${ }^{17}$ The findings using our sample that extends the time period to 2008 confirm the possibility that abnormal returns of price momentum could arise because of a delayed over-reaction to information that pushes the prices of winners (losers) above (below) their long-term values. For earnings momentum, however, no significant long-run reversal is evident though the results show small negative return in the third year after portfolio formation.

\footnotetext{
${ }^{17}$ These results are slightly different from those reported by Jegadeesh and Titman (1993, 2001), who find that price momentum profits are significantly positive for both the first and the second six months after portfolio formation. The differences between our results and those of by Jegadeesh and Titman $(1993,2001)$ might be due to the fact that our sample includes only firms covered by analysts, which tend to be large firms, and that momentum profits are much smaller among large firms.
} 
As indicated in Table 6, the main driving force for momentum profitability is the net effect of the cash flow return component and the discount rate return component. Compared to price momentum returns, earning momentum returns display longer cash flow return persistence. On the other hand, negative discount rate returns are more substantial for price momentum which enhances the reversal effect. Observing the pre-formation discount rate news, one possible interpretation is that the price momentum strategy picks temporary winners driven partially by discount rate news which reverts out of the sample. Since the earnings momentum sort does not tend to sort stocks based on past discount rate news, such reversion is not strong enough to fully offset the persistence in cash flow news. The cumulative profits of the price and earnings momentum in long holding horizons once more underline their differences. Of the two momentum anomalies, price momentum is more likely to be explained by delayed over-reaction (i.e., Jegadeesh and Titman (2001)), which is corrected eventually as negative discount rate news in the post-formation period counteracts the large positive discount rate news component in the pre-formation period.

\subsection{Calendar-time properties of momentum profits}

Cooper et al. (2004) show that momentum profits depend on the state of the market, and may be related to investor overconfidence. In particular, they find that there are no momentum profits following negative market returns. We examine the time-series behavior of our decomposed return components in calendar time. As presented in Figure 3, for both price momentum and earnings momentum, momentum profits are positive during most of the sample period from 1985 to 2008. In addition, there are large time-series variations in the magnitude of momentum profits. Return decomposition is used to investigate the role of return components in driving the calendar-time cross-sectional profits. In untabulated results, we find that the time-series 
correlation between the momentum profit and the spread in the discount rate return component between the winner and loser decile portfolios is about 70\%. The time-series correlation between the momentum profit and the spread in the cash flow return component between the winner and loser decile portfolios is only about $30 \%$. The momentum return and the discount rate return parallel to each other indicating that momentum profits are substantially better correlated with the discount rate return dispersion than with the cash flow return dispersion between the winner and loser portfolios.

This evidence could be regarded as an example of the implications in Chen and Zhao (2008). The time-series variations in price momentum profits (with a six-month holding horizon) are dominated by discount rate news. Since price momentum profits mainly come from the cash flow return component, which is partially attenuated or offset by the discount rate return component, smaller absolute discount rate dispersion between the winner and loser portfolios indicates higher sentiment and less risk adjustment which induce higher momentum profitability. The higher the overall market sentiment, the larger the spread in momentum profits that is driven by the persistence in good cash flow news but smaller offsets from discount rate news. Investor sentiment reflects investor perception about the risk of earnings improvement (drop) for winners (losers) and higher. For example, during the internet bubble around year 2000, the graph shows a close to zero discount rate return adjustment and thus quite substantial momentum profitability. The calendar-time cash flow return dispersion between the winner and loser portfolios is relatively stable and positive suggesting that persistence in cash flow news is the reason why momentum strategy works in average times. 


\section{Robustness Checks}

\subsection{Accounting valuation models and return decomposition}

These return decompositions assume that the valuation model represents how the marginal investors price a stock and analyst earnings forecasts reflect or determine how the marginal investors think about a firm's future earnings prospects. We test the results using each of the four valuation models individually and reexamine the expected return components, the cash flow return components, and the discount rate return components for the momentum strategies. The results (not tabulated) confirm that the conclusions remain unchanged regardless of the valuation model. Given that the four valuation models have different assumptions about firm earnings growth mechanisms, our results are unlikely to be driven by the specification of one particular valuation model. The decomposition method aims to quantify stock price changes rather than to target a stock at the correct valuation level. As long as the model specification does not distort the relative contributions of return components, our results based on the valuation models should be reliable.

The other crucial issue is whether analysts' earnings forecasts reflect the market's expectation. Systematic bias could arise when analysts' earnings forecasts lag behind the market's expectations for the momentum portfolios. If it is the case, we would tend to underestimate the earnings forecasts of the winner portfolio, so the estimated implied cost of equity for the winner portfolio would be biased downward at portfolio formation. This would hinder uncovering any risk explanation for momentum anomalies. However, the findings by Stickel (1991) and Gleason and Lee (2003) among others suggest that analysts' forecast revisions are price informative and that a substantial portion of the price adjustment is delayed. This could mean that the market does not fully assimilate the information in earnings forecast 
revisions. The effect would be a bias toward finding a risk explanation, overestimating the earnings and thus the implied cost of equity for the winner portfolio at portfolio formation. Consensus has not been reached on whether the market can forecast earnings ahead of analysts or analyst forecasts shape the market's expectation. Either way, by the co-movement of earnings forecasts and price movements, the results convince us that the significant profitability of price and earnings momentum is from cash flow return contribution. The evidence that the ex-ante expected return measure largely replicates most of the other cross-sectional anomalies (Wu and Zhang (2010)) also supports using valuation models. ${ }^{18}$

Regarding the time series behavior of return components in driving the momentum returns, the sudden reversal of discount rate returns for price momentum around portfolio formation time may appear as a surprise at first sight. Due to the constraints from the valuation models, we need proper earnings forecasts in order to back out positive discount rates (or otherwise excluded from our sample). To relax the concern about noisy estimates and extreme values of discount rates, we replicate our results by excluding from the sample those stocks that have highest $10 \%$ or lowest $10 \%$ discount rate estimates. The conclusions still hold as before. In a different check, we decompose stock returns based on six month horizons instead of monthly horizons. Untabulated results suggest that the substantial reversal in discount rate returns remain unchanged. To understand the economic meaning of the reversal in discount rate returns, we suggest two directions to pursue. In the time series, if we assume discount rate returns are transient, stocks that experience substantial recent discount rate shocks will be very likely to experience subsequent negative discount rate shocks so that on average their cumulative total returns reflect

\footnotetext{
${ }^{18} \mathrm{Wu}$ and Zhang use dividend discounting models to show that $e x$-ante expected return estimates are similar in magnitude to the realized returns of hedge portfolios formed on book-to-market equity, composite issuance, net stock issues, abnormal investment, asset growth, earnings surprises, and failure probability.
} 
major impact from cash flow news only. Second, price momentum strategy selects stocks based on in the sample price performances and holds them out of the sample. It is natural that the sorting period performances are much greater than the holding period. This implies that selecting stocks with past discount rate returns and cash flow returns that are both positive is much of an easier job than finding stocks that outperform in both types of returns ex-post. We thus suggest applying distinct ways to understand return patterns before and after portfolio formation. The holding period return pattern for price momentum strategy indicates large cash flow news that is persistent and also considerable price anchoring behavior of marginal investors.

\subsection{Momentum strategies and information uncertainty}

As Zhang (2006) and Verardo (2009), among others, have documented, greater information uncertainty or greater investor disagreement is correlated with stronger price momentum and earnings momentum. ${ }^{19}$ We extend our original tests by examining the role of different return components of momentum portfolios with different degrees of information uncertainty. The results are presented in Table 7. We use the standard deviation (SIGMA) calculated from weekly stock excess returns to proxy for information uncertainty. Each month, all stocks are sorted into quintiles (U1 to U5) based on (SIGMA) calculated from weekly excess returns over the previous year, and the stocks in each SIGMA quintile are then further sorted into five groups (M1 to M5) based on their past six-month compounded total returns. The portfolios are held for six months

\footnotetext{
${ }^{19}$ A number of theoretical papers have shown that return continuation such as price or earnings momentum can be generated by investor heterogeneity or information uncertainty. See, for example, Allen, Morris, and Shin (2006), Banerjee, Kaniel, and Kremer (2009), and Makarov and Rytchkov (2009) for the rational models and Hong and Stein $(1999,2000,2007)$ for the behavioral models.
} 
post formation. Results based on using other information uncertainty proxies deliver similar conclusions. $^{20}$

If the behavioral explanation holds, when information uncertainty is greater and the market incorporates cash flow information more slowly, the momentum profits should be larger in terms of total returns or the cash flow return component. The magnitude of the negative spread in the discount rate return component between winners and losers should also be larger as the risk adjustments to offset the role of cash flow contribution should be larger to represent marginal investors who tend to exhibit more price anchoring. The results in Table 7 show that the price momentum spread is $1.16 \%$ per month in the highest information uncertainty group (U5) as compared to $-0.11 \%$ per month in the lowest information uncertainty group (U1). In the cash flow return component, the spread is $5.26 \%$ in U5 and $1.52 \%$ in U1. In the discount rate return component, the spread between winners and losers is $-3.95 \%$ in U5 and $-1.58 \%$ in U1. These results suggest that information uncertainty amplifies the roles of cash flow news and discount rate news in price momentum strategies. This supports the behavioral explanation that return innovations rather than expected returns drive momentum profits, especially when the market incorporates cash flow innovations more slowly in high information uncertainty environments. ${ }^{21}$

[Insert Table 7 here]

Table 8 reports the test results for earnings momentum. The results are similar to those for price momentum. Confirming findings by Zhang (2006), earnings momentum profits increase with information uncertainty. The earnings momentum profit in the highest information

\footnotetext{
${ }^{20}$ Following Zhang (2006), we also use firm age and cash flow volatility defined as the standard deviation of cash flow from operations over the past five years to proxy for information uncertainty.

${ }^{21}$ We obtain similar results for both price and earnings momentums when we form portfolios based on sorting past returns first then information uncertainty or sorting past returns and information uncertainty independently.
} 
uncertainty group (U5) is $0.71 \%$ per month as compared to $0.22 \%$ per month in the lowest information uncertainty group (U1). For the cash flow return component, the spread between the winners and losers is $2.06 \%$ in the U5 group and $0.58 \%$ in the U1 group. For the discount rate return component, the spread between winners and losers is $-1.30 \%$ in the U5 group and only $0.32 \%$ in the U1 group. As predicted by behavioral models, greater information uncertainty seems to lead to higher earnings momentum profits in total returns and cash flow returns. On the other hand, the price anchoring behavior of the marginal investors seem to generate a larger negative discount rate return spread for earnings momentum strategies when information uncertainty is high. The effect from the expected return component is relatively tiny.

[Insert Table 8 here]

\section{Conclusion}

The rational versus behavioral explanations for price and earnings momentum anomalies are tested using a unified return decomposition framework. Accounting valuation models are used to quantify contributions of each of the expected return component, the cash flow return component, and the discount rate return component in driving momentum profits. We provide more insights relating to the differences between price momentum and earnings momentum. Since momentum anomalies do not exist ex ante as documented by Wu and Zhang (2009), our results offer one explanation by exploring the dynamics of the return components from the sorting period to the holding period. Sorting stocks based on past price performances tends to sort on past cash flow news as well as past discount rate news so that past winners, after experiencing positive discount rate news, bear a lower implied cost of equity capital than past losers. The expected future return is proxied by the implied cost of equity capital when forming portfolios; thus, risk-based arguments will predict that winners underperform losers in the holding period, but this is not 
born by the evidence. Momentum profits, therefore, cannot be reconciled with the risk-based explanations.

Though the time-series variations in momentum portfolio returns are mainly driven by discount rate news, consistent with findings in Chen and Zhao (2010), it is the net effect of a positive cash flow return component and a negative discount rate return component that dominate momentum profits. In the cross section, the cash flow return spread between the winner group and the loser group is much larger than the corresponding total return spread. Discount rate news partially offset the large profits due to cash flow news.

Comparing the characteristics of price momentum with those of earnings momentum yields some interesting results. In particular, the difference in the pre-formation discount rate news between winner and loser portfolios could have important implications over long holding horizons after portfolio formation. Specifically, price momentum profitability displays a longterm reversal, which is attributable to the reversal in both cash flow news and discount rate news. But this is not the case for earnings momentum, for which positive cash flow returns persist longer and no reversal in earnings momentum profit is observed. The properties of sorting period discount rate returns then account for the fact that temporary winners are chosen in the price momentum case while permanent winners are selected in the earnings momentum case. For both momentum strategies, overall, our results suggest that behavioral underlying forces are more plausible. 


\section{References}

Allen, Frank; Stephen Morris; and Hyun Song Shin, 2006, Beauty contests and iterated expectations in asset markets, Review of Financial Studies 19, 719-752.

Ball, Ray, and Philip Brown, 1968, An empirical evaluation of accounting income numbers, Journal of Accounting Research 6, 159-178.

Banerjee, Snehal; Ron Kaniel; and Ilan Kremer, 2009, Price drift as an outcome of differences in higher-order beliefs, Review of Financial Studies 22, 3707-3734.

Barberis, Nicholas, Andrei Shleifer, and Robert Vishny, 1998, A model of investor sentiment, Journal of Financial Economics 49, 307-343.

Berk, Jonathan B., Richard C. Green, and Vasant Naik, 1999, Optimal investment, growth options, and security returns, Journal of Finance 54, 1553-1607.

Bernard, Victor L., and Jacob K. Thomas, 1990, Evidence that stock prices do not fully reflect the implications of current earnings for future earnings, Journal of Accounting and Economics 13, 305-340.

Campbell, John Y., 1991, A variance decomposition for stock returns, Economic Journal 101, 157-179.

Campbell, John Y., and Robert J. Shiller, 1988, The dividend-price ratio and expectations of future dividends and discount factors, Review of Financial Studies 1, 195-228.

Campbell, John Y., and Tuomo Vuolteenaho, 2004, Bad beta, good beta, American Economic Review 94, 1249-1275.

Chan, Louis K.C., Narasimhan Jegadeesh, and Josef Lakonishok, 1996, Momentum strategies, Journal of Finance 51, 1681-1713.

Chen, Kevin C.W., Zhihong Chen, and K.C. John Wei, 2009, "Agency costs of free cash flows and the effect of shareholder rights on the implied cost of capital," Journal of Financial and Quantitative Analysis, forthcoming.

Chen, Long, and Xinlei Zhao, 2009, Return decomposition, Review of Financial Studies, forthcoming.

Chen, Long, and Xinlei Zhao, 2010, What drives stock price movement? Working paper.

Chordia, Tarun, and Lakshmanan Shivakumar, 2006, Earnings and price momentum, Journal of Financial Economics 80, 627-656. 
Chui, Andy C.W., Sheridan Titman, and K.C. John Wei, 2010, Individualism and momentum around the world, Journal of Finance 65, 361-392.

Claus, James, and Jacob Thomas, 2001, Equity premia as low as three percent? Evidence from analysts' earnings forecasts for domestic and international stock markets, Journal of Finance 56, $1629-1666$.

Conrad, Jennifer and Gautam Kaul, 1998, An anatomy of trading strategies, Review of Financial Studies 11, 489-519.

Cooper, Michael J., R.C. Gutierrez Jr., and A. Hameed, 2004, Market states and momentum, Journal of Finance 59, 1345-1365.

Da, Zhi, and Mitchell C. Warachka, 2009, Cashflow risk, systematic earnings revisions, and the cross-section of stock returns, Journal of Financial Economics 94, 448-468.

Daniel, Kent, David Hirshleifer, and Avanidhar Subrahmanyam, 1998, Investor psychology and security market under- and over-reactions, Journal of Finance 53, 1839-1885.

Easton, Peter D., 2004, PE ratios, PEG ratios, and estimating the implied expected rate of return on equity capital, The Accounting Review 79, 73-95.

Fama, Eugene F., and Kenneth R. French, 1992, The cross-section of expected stock returns, Journal of Finance 47, 427-465.

Fama, Eugene F., and Kenneth R. French, 1993, Common risk factors in the returns on stocks and bonds, Journal of Financial Economics 33, 3-56.

Gebhardt, William R., Charles M. C. Lee, and Bhaskaran Swaminathan, 2001, Toward an implied cost of capital, Journal of Accounting Research 39, 135-176.

Givoly, Dan, and Josef Lakonishok, 1980, Financial analysts' forecasts of earnings: Their value to investors, Journal of Banking and Finance 4, 221-233.

Gleason, Cristi A., and Charles M.C. Lee, 2003, Analyst forecast revisions and market price discovery, The Accounting Review 78, 193-225.

Griffin, John M., Xiuqing Ji, and J. Spencer Martin, 2003, Momentum investing and business cycle risk: Evidence from pole to pole, Journal of Finance 58, 2515-2547.

Hail, Luzi, and Christian Leuz, 2006, International differences in cost of equity: do legal institutions and securities regulation matter? Journal of Accounting Research 44, 485-531.

Hong, Harrison, Terence Lim, and Jeremy C. Stein, 2000, Bad news travels slowly: Size, analyst coverage, and the profitability of momentum strategies, Journal of Finance 55, 265-295. 
Hong, Harrison, and Jeremy C. Stein, 1999, A unified theory of underreaction, momentum trading, and overreaction in asset markets, Journal of Finance 54, 2143-2184.

Hong, Harrison, and Jeremy C. Stein, 2007, Disagreement and the stock market, Journal of Economic Perspectives 21, 109-128

Jegadeesh, Narasimhan, and Sheridan Titman, 2002, Cross-sectional and time-series determinants of momentum returns, Review of Financial Studies 15, 143-157.

Jegadeesh, Narasimhan, and Sheridan Titman, 2001, Profitability of momentum strategies: An evaluation of alternative explanations, Journal of Finance 56, 699-720.

Jegadeesh, Narasimhan, and Sheridan Titman, 1993, Returns to buying winners and selling losers: Implications for stock market efficiency, Journal of Finance 48, 65-91.

Johnson, Timothy C., 2002, Rational momentum effects, Journal of Finance 57, 585-608.

Lo, Andrew W., and A. Craig MacKinlay, 1990, When are contrarian profits due to stock market overreaction? Review of Financial Studies 3, 175-205.

Makarov, Igor, and Oleg Rytchkov, 2009, Forecasting the forecasts of others: Implications for asset pricing, Working Paper, London Business School and University of Texas at Austin.

Ohlson, James A., and Beate E. Juettner-Nauroth, 2005, Expected EPS and EPS growth as determinants of value, Review of Accounting Studies 10, 349-365.

Pástor, Luboš, Meenakshi Sinha, and Bhaskaran Swaminathan, 2008, Estimating the intertemporal risk-return tradeoff using the implied cost of capital, Journal of Finance 63, 28592897.

Rouwenhorst, K. Geert, 1998, International momentum strategies, Journal of Finance 53, 267284.

Stickel, Scott E., 1991, Common stock returns surrounding earnings forecast revisions: More puzzling evidence, The Accounting Review 66, 402-416.

Verardo, Michela, 2009, Heterogeneous beliefs and momentum profits, Journal of Financial and Quantitative Analysis 44, 795-882.

Wu, Jin G., and Lu Zhang, 2010, Do anomalies exist ex ante? Working paper.

Zhang, X. Frank, 2006, Information uncertainty and stock returns, Journal of Finance 61, 105137. 


\section{Appendix 1: Description and Implementation of Valuation Models}

Four valuation models are used in the return decomposition:

I/B/E/S analysts' forecasts are used to proxy for the market expectation of the firm's earnings.

1) Gebhardt, Lee, and Swaminathan (2001)

$P_{t}^{*}=B_{t}+\sum_{i=1}^{T-1} \frac{\left(F R O E_{t+i}-R_{g l s}\right)^{*} B_{t+i-1}}{\left(1+R_{g l s}\right)^{i}}+\frac{\left(F R O E_{t+T}-R_{g l s}\right)^{*} B_{t+T-1}}{\left(1+R_{g l s}\right)^{T-1} * R_{g l s}}$

$P_{t}$ is the price at month t. $B_{t}$ is the book value of equity (Compustat item \#60) per share at month $t$ and $T$ is set at 12. FROE is the forecast earnings per share divided by the book value of equity per share for the first three years and declines linearly to an equilibrium return on equity from the fourth year to the twelfth year. The equilibrium return on equity is calculated as the past ten-year industry-level median return on equity. The industry level $R O E$ is winsorized to be between the risk-free rate and 0.3 . The book value of equity is estimated using the clean surplus condition that is $B_{t+1}=B_{t}+E P S_{t+1}-D P S_{t+1}$.

$D P S_{t+i}$ is equal to $E P S_{t+i}$ multiplied by POUT . POUT is the forecast dividend payout ratio, i.e., (item \#21 divided by item \#237) or (item \#21 divided by item \#6*0.06 if \#237 is missing).

$P_{t}^{*}=P_{t} /\left(1+R_{g l s}\right)^{\text {lag } / 12}$ is used to adjust the stock price so that $P_{t}^{*}$ is one year before the $\mathrm{I} / \mathrm{B} / \mathrm{E} / \mathrm{S}$ oneyear-ahead earnings forecast date (fpedats). The implied cost of capital, $R_{g l s}$, is solved to equate the left hand side of the equation to the right hand side.

2) Claus and Thomas (2001)

$$
P_{t}^{*}=B_{t}+\sum_{i=1}^{5} \frac{\left(\text { FEPS }_{t+i}-R_{c t} * B_{t+i-1}\right)}{\left(1+R_{c t}\right)^{i}}+\frac{\left(\text { FEPS }_{t+5}-R_{c t} * B_{t+4}\right) *\left(1+g_{l t}\right)}{\left(R_{c t}-g_{l t}\right) *\left(1+R_{c t}\right)^{5}}
$$

The data definitions follow those of model 1. FEPS ${ }_{t+i}$ is calculated using the long-term earnings growth rate from $\mathrm{I} / \mathrm{B} / \mathrm{E} / \mathrm{S}$ or the growth rate implied by $E P S_{t+2}$ and $E P S_{t+3}$. The long-term abnormal earnings growth rate, $g_{l t}$, is calculated using the contemporaneous risk-free rate minus 3 percent. The implied cost of capital, $R_{c t}$, is solved to equate the left hand side of the equation to the right hand side.

3) Ohlson and Juettner-Nauroth (2005) as implemented by Code and Mohanram (2003)

$$
P_{t}^{*}=\frac{E\left(E P S_{t+1}\right)}{R_{o j}}+\frac{E\left(E P S_{t+1}\right) * E\left[g_{s t}-R_{o j} *(1-P O U T)\right]}{R_{o j} *\left(R_{o j}-g_{l t}\right)}
$$

The data definitions follow those of model 2. The short-term earnings growth rate, $g_{s t}$, is the average of the short-term earnings growth rate implied by $E P S_{t+1}, E P S_{t+2}$ and the analysts' forecast long-term growth rate. The long-term earnings growth rate is calculated using the contemporaneous risk-free rate 
minus 3 percent. The implied cost of capital, $R_{o j}$, is solved to equate the left hand side of the equation to the right hand side.

4) The Modified PEG ratio model by Easton (2004)

$$
P_{t}^{*}=\frac{E\left(E P S_{t+1}\right)}{R_{m p e g}}+\frac{E\left(E P S_{t+1}\right) * E\left[g_{s t}-R_{m p e g} *(1-P O U T)\right]}{R_{m p e g}^{2}}
$$

The data definitions follow those of model 3. The implied cost of capital $R_{m p e g}$ is solved to equate the left hand side of the equation to the right hand side. 


\section{Table 1. Summary statistics and correlations for cash flow and discount rate return components}

Panel A reports the number of firms by year. The sample is from 1985 to 2008 with financial firms excluded. Panel B shows the Pearson correlations between the cash flow return component (CFret), the discount rate return component (DRret), and the corresponding estimates using each of the four valuation models. GLS, CT, ROJ, MPEG represent the estimates using the models of Gebhardt, Lee, and Swaminathan (2001), Claus and Thomas (2001), Ohlson and Juettner-Nauroth (2005), and the Modified PEG ratio model of Easton (2004), respectively. CFret, DRret, and Eret are from the same valuation model using the median discount rate estimates among the four models. Panel $\mathrm{C}$ presents the summary statistics for the cash flow return component, the discount rate return component, the expected return component, and the total return. Panel D reports inter correlations among CFret, DRret, Eret, and the total return. The return components are estimated monthly.

\begin{tabular}{rr}
\hline Panel A: Number of firms by year & \\
\hline 1985 & $\mathrm{~N}$ \\
\hline 1986 & 1147 \\
1987 & 1255 \\
1988 & 1302 \\
1989 & 1350 \\
1990 & 1328 \\
1991 & 1322 \\
1992 & 1358 \\
1993 & 1446 \\
1994 & 1621 \\
1995 & 1806 \\
1996 & 1959 \\
1997 & 2090 \\
1998 & 2220 \\
1999 & 2254 \\
2000 & 2175 \\
2001 & 1969 \\
2002 & 1785 \\
2003 & 1706 \\
2004 & 1706 \\
2005 & 1733 \\
2006 & 1754 \\
2007 & 1755 \\
2008 & 1765 \\
Average & 1690 \\
& 1687 \\
\hline
\end{tabular}


Table 1 (continued)

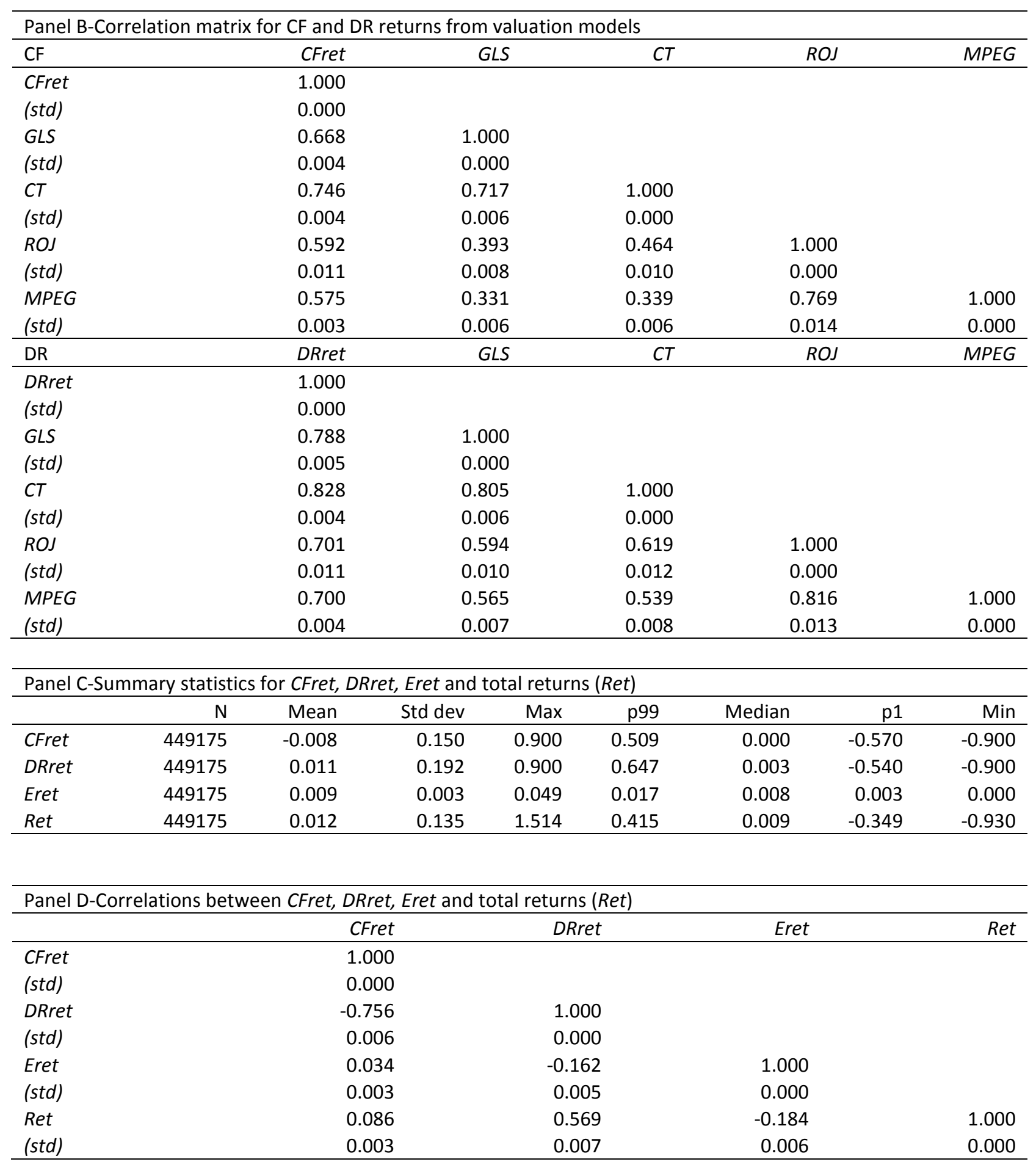




\section{Table 2. Decomposed return components of price momentum and earnings momentum}

Panel A reports average monthly returns for portfolios formed based on past return performance. Each month all stocks are sorted into deciles based on their past six-month cumulative stock returns. Decile 1 (D1) groups the past losers and Decile 10 (D10) the past winners. D10-D1 is the hedge portfolio that longs D10 and shorts D1. The portfolios are held for six months post formation. Equal-weighted average monthly returns are reported. Ret, CFret, DRret, and Eret are the total return, the cash flow return component, the discount rate return component, and the expected return component, respectively. The sample period is from 1985 to 2008. Panel B reports average monthly returns for portfolios formed based on earning surprises (SUE). SUE is quantified as the most recent quarterly earnings per share minus earnings per share four quarters ago divided by the standard deviation of the unexpected earnings from the prior eight quarters. Each month the stocks are sorted into deciles based on the most recent past SUE. The portfolios are held for six months post formation. Equal-weighted average monthly returns are reported. Ret, CFret, DRret, Eret are in percentage. The $t$-statistics are in parentheses.

\begin{tabular}{lrrrr}
\hline Panel A:Price momentum & \multicolumn{3}{r}{} & \\
\hline & Ret & CFret & DRret & Eret \\
\hline D1(lowest) & 0.7369 & -3.6522 & 3.4258 & 0.9634 \\
D2 & 0.9434 & -2.1443 & 2.1793 & 0.9083 \\
D3 & 1.0063 & -1.4922 & 1.6180 & 0.8805 \\
D4 & 1.0806 & -1.0482 & 1.2662 & 0.8625 \\
D5 & 1.1130 & -0.6964 & 0.9598 & 0.8496 \\
D6 & 1.0836 & -0.4581 & 0.7030 & 0.8387 \\
D7 & 1.0300 & -0.2271 & 0.4253 & 0.8317 \\
D8 & 1.1255 & 0.0316 & 0.2690 & 0.8249 \\
D9 & 1.1917 & 0.3636 & 0.0073 & 0.8209 \\
D10(highest) & 1.5913 & 1.2500 & -0.4762 & 0.8175 \\
D10-D1 & 0.8543 & 4.9022 & -3.9020 & -0.1459 \\
t-statistic & $(2.85)$ & $(27.15)$ & $(-11.77)$ & $(-6.43)$ \\
\hline Panel B:Earnings momentum & & & & \\
\hline & Ret & CFret & DRret & Eret \\
\hline D1(lowest) & 0.7907 & -1.7489 & 1.6541 & 0.8854 \\
D2 & 0.8947 & -1.4911 & 1.5092 & 0.8766 \\
D3 & 1.0191 & -1.2645 & 1.4109 & 0.8728 \\
D4 & 1.0216 & -1.0863 & 1.2394 & 0.8685 \\
D5 & 1.1419 & -0.7890 & 1.0699 & 0.8611 \\
D6 & 1.1546 & -0.6131 & 0.9118 & 0.8558 \\
D7 & 1.1799 & -0.4073 & 0.7381 & 0.8491 \\
D8 & 1.2038 & -0.4364 & 0.7954 & 0.8447 \\
D9 & 1.2292 & -0.2337 & 0.6290 & 0.8339 \\
D10(highest) & 1.2142 & 0.0217 & 0.3862 & 0.8063 \\
D10-D1 & 0.4235 & 1.7706 & -1.2680 & -0.0791 \\
t-statistic & $(2.99)$ & $(16.02)$ & $(-6.93)$ & $(-8.86)$ \\
\hline
\end{tabular}


Table 3. Price momentum during the pre- and post-formation periods

This table presents month-by-month returns for the price momentum portfolio (D10-D1), the loser portfolio (D1), and the winner portfolio (D10). All stocks are sorted into deciles based on their past six-month cumulative returns at the end of formation month (Month 0). Each of the decomposed return components is estimated from six months before portfolio formation to six months after portfolio formation. D1 is the past loser decile portfolio and D10 is the past winner decile portfolio. D10-D1 denotes a hedge portfolio that longs D10 and shorts D1. Equal-weighted returns are reported. The sample period is from 1985 to 2008. All returns are in percentage. The $t$-statistics are in parentheses.

\begin{tabular}{|c|c|c|c|c|c|c|c|c|c|c|c|c|}
\hline \multicolumn{7}{|c|}{ Price momentum } & \multicolumn{6}{|l|}{ Month } \\
\hline D10-D1 & -5 & -4 & -3 & -2 & -1 & 0 & 1 & 2 & 3 & 4 & 5 & 6 \\
\hline Ret & 16.4180 & 15.8400 & 15.9410 & 16.1880 & 16.5070 & 17.5840 & 0.4700 & 1.1040 & 0.9740 & 0.9110 & 0.9430 & 0.9410 \\
\hline$t$-statistic & $(48.21)$ & $(48.41)$ & $(48.02)$ & (45.79) & $(41.85)$ & $(40.51)$ & $(1.24)$ & (3.14) & (2.96) & $(2.86)$ & (3.17) & (3.23) \\
\hline CFret & 2.5980 & 4.8130 & 6.3200 & 7.3510 & 8.4220 & 9.0890 & 8.0620 & 6.2180 & 5.0320 & 4.1390 & 3.2950 & 2.6720 \\
\hline t-statistic & (16.69) & $(27.25)$ & (32.29) & $(36.82)$ & $(38.12)$ & $(38.64)$ & (34.34) & $(30.07)$ & $(24.65)$ & (19.17) & $(16.80)$ & (13.97) \\
\hline DRret & 13.8730 & 11.1300 & 9.7670 & 9.0190 & 8.3010 & 8.7490 & -7.3810 & -4.9360 & -3.9080 & -3.1000 & -2.2410 & -1.6310 \\
\hline t-statistic & (37.39) & (31.51) & $(26.10)$ & $(23.73)$ & (19.47) & (19.06) & $(-17.69)$ & $(-13.00)$ & $(-10.70)$ & $(-8.49)$ & $(-6.60)$ & $(-4.88)$ \\
\hline Eret & -0.0540 & -0.1040 & -0.1460 & -0.1820 & -0.2160 & -0.2540 & -0.2110 & -0.1780 & -0.1500 & -0.1290 & -0.1110 & -0.1000 \\
\hline t-statistic & $(-3.65)$ & $(-6.73)$ & $(-8.36)$ & $(-9.28)$ & $(-9.59)$ & $(-9.64)$ & $(-8.44)$ & $(-7.43)$ & $(-6.45)$ & $(-5.68)$ & $(-5.11)$ & $(-4.63)$ \\
\hline \multicolumn{13}{|l|}{ D1 } \\
\hline Ret & -6.6520 & -6.4610 & -6.5250 & -6.7500 & -6.9690 & -7.6840 & 1.0990 & 0.6140 & 0.5850 & 0.6840 & 0.6640 & 0.7040 \\
\hline t-statistic & $(-15.88)$ & $(-14.76)$ & $(-14.36)$ & $(-14.34)$ & $(-13.92)$ & $(-15.04)$ & (2.16) & (1.26) & (1.24) & (1.47) & (1.44) & (1.53) \\
\hline CFret & -1.9670 & -3.2550 & -4.1970 & -4.8900 & -5.6460 & -6.0600 & -5.5730 & -4.3600 & -3.6590 & -3.1840 & -2.7080 & -2.3890 \\
\hline t-statistic & $(-12.84)$ & $(-20.40)$ & $(-24.39)$ & $(-27.48)$ & $(-29.88)$ & $(-31.01)$ & $(-29.30)$ & $(-24.94)$ & $(-21.37)$ & $(-18.50)$ & $(-16.00)$ & $(-14.25)$ \\
\hline DRret & -5.6060 & -4.1540 & -3.2980 & -2.8510 & -2.3330 & -2.6570 & 5.6690 & 3.9910 & 3.2780 & 2.9150 & 2.4310 & 2.1610 \\
\hline$t$-statistic & $(-13.17)$ & $(-9.09)$ & $(-6.76)$ & $(-5.85)$ & $(-4.54)$ & $(-5.19)$ & (10.87) & $(8.20)$ & (6.87) & $(6.20)$ & (5.31) & $(4.66)$ \\
\hline Eret & 0.9210 & 0.9480 & 0.9700 & 0.9910 & 1.0100 & 1.0320 & 1.0040 & 0.9820 & 0.9660 & 0.9520 & 0.9410 & 0.9320 \\
\hline t-statistic & (29.58) & $(30.35)$ & (30.61) & (30.79) & $(30.52)$ & $(29.85)$ & $(29.50)$ & (29.14) & $(28.64)$ & (28.39) & (28.39) & $(28.20)$ \\
\hline \multicolumn{13}{|l|}{ D10 } \\
\hline Ret & 9.7650 & 9.3780 & 9.4170 & 9.4370 & 9.5370 & 9.8990 & 1.5690 & 1.7180 & 1.5590 & 1.5940 & 1.6070 & 1.6460 \\
\hline t-statistic & $(22.60)$ & (22.79) & (23.65) & (23.19) & (23.83) & (23.94) & (4.01) & (4.33) & (3.81) & (3.78) & (3.79) & (3.85) \\
\hline CFret & 0.6310 & 1.5580 & 2.1230 & 2.4610 & 2.7760 & 3.0290 & 2.4890 & 1.8580 & 1.3730 & 0.9560 & 0.5870 & 0.2830 \\
\hline t-statistic & $(3.80)$ & $(9.32)$ & $(12.55)$ & (14.45) & $(15.36)$ & (16.35) & (13.16) & (9.96) & (7.32) & (4.73) & (3.11) & $(1.48)$ \\
\hline DRret & 8.2670 & 6.9760 & 6.4690 & 6.1680 & 5.9680 & 6.0920 & -1.7120 & -0.9450 & -0.6300 & -0.1850 & 0.1910 & 0.5300 \\
\hline t-statistic & (18.34) & $(16.20)$ & (15.68) & (14.65) & (14.22) & $(14.36)$ & $(-4.20)$ & $(-2.27)$ & $(-1.52)$ & $(-0.43)$ & $(0.44)$ & (1.22) \\
\hline Eret & 0.8670 & 0.8440 & 0.8250 & 0.8090 & 0.7930 & 0.7780 & 0.7920 & 0.8050 & 0.8150 & 0.8230 & 0.8290 & 0.8330 \\
\hline$t$-statistic & $(30.42)$ & $(29.81)$ & $(29.28)$ & $(28.74)$ & $(28.35)$ & $(27.92)$ & $(28.40)$ & $(28.62)$ & $(29.03)$ & $(29.51)$ & $(30.31)$ & $(31.02)$ \\
\hline
\end{tabular}


Table 4. Earnings momentum during the pre- and post-formation periods

This table presents month-by-month returns for the earnings momentum portfolio (D10-D1), the lowest SUE portfolio (D1), and the highest SUE portfolio (D10), All stocks are sorted into deciles based on their most recent past SUE at the end of formation month (Month 0). SUE is defined in Table 2. The table also reports monthly decomposed return components from six months before portfolio formation to six months after portfolio formation. D1 denotes the past lowest earnings surprise decile portfolio and D10 denotes the past highest earnings surprise decile portfolio. D10-D1 denotes a hedge portfolio that longs D10 and shorts D1. Equal-weighted returns are reported. The sample period is from 1985 to 2008. All returns are in percentage. The $t$-statistics are in parentheses.

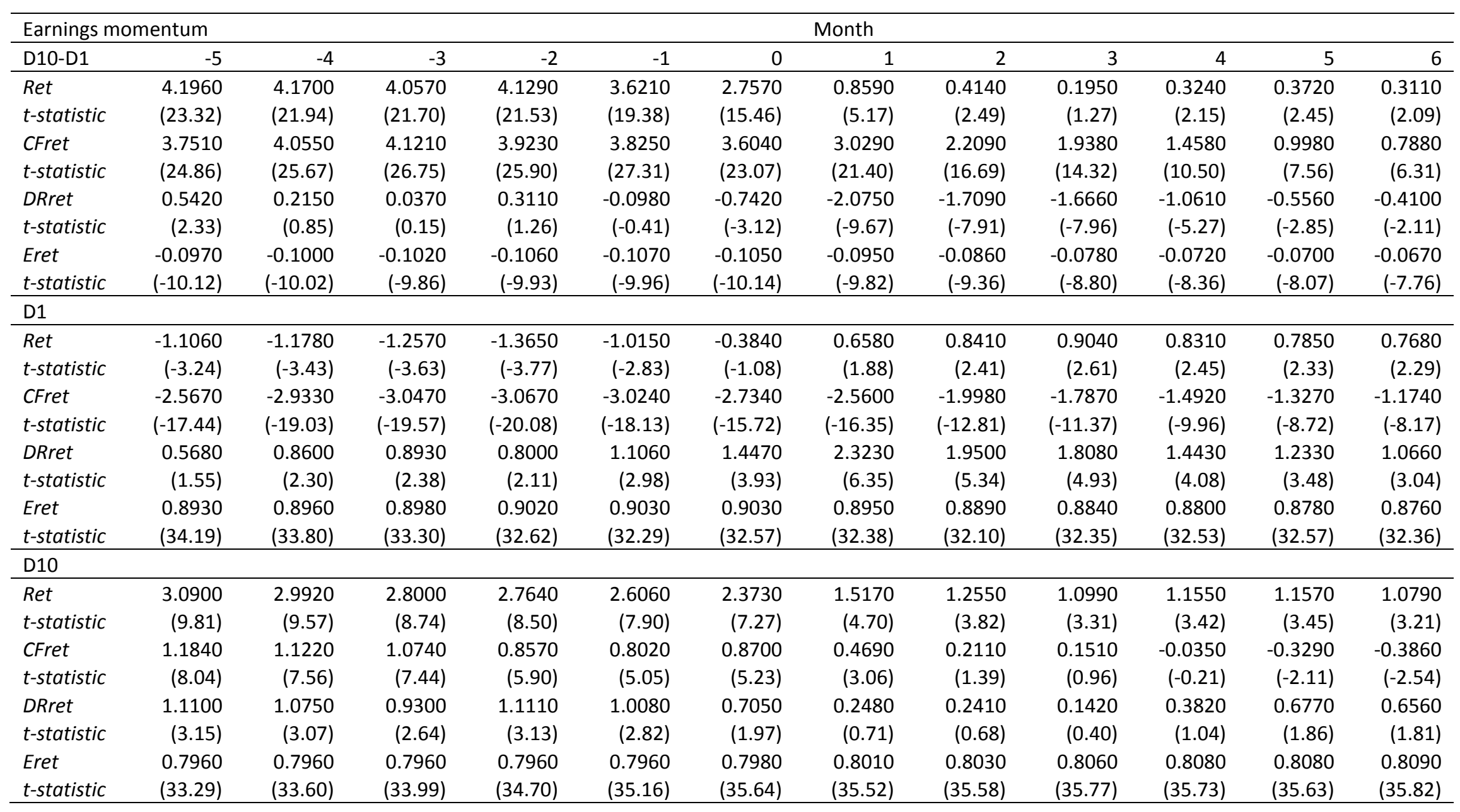




\section{Table 5. Characteristics of price momentum portfolios and earnings momentum portfolios}

Panels A and B of this table present the characteristics of the price momentum decile portfolios and the earnings momentum decile portfolios at the time of portfolio formation, respectively. For price momentum, all stocks are sorted into deciles based on their past six-month cumulative returns. For earnings momentum, all stocks are sorted into deciles based on their most recent past standardized unexpected earnings (SUE) as defined in Table 2. Mom Port 1 denotes the losers/low SUE group and Mom Port 10 denotes the winners/high SUE group. Ret stands for the mean monthly return in the past six months. CFret stands for the mean monthly cash flow return component in the past six months. DRret stands for mean monthly discount rate return component in the past six months. Eret stands for mean monthly expected return in the past six months. Ret, CFret, DRret, Eret are in percentage. $R$ stands for the implied cost of equity (annualized) measured at portfolio formation. $G r$ stands for the I/B/E/S long-term growth rate at the formation month (Month 0). SUE stands for the most recent past standardized unexpected earnings at the time of formation. The sample period is from 1985 to 2008.

\begin{tabular}{|c|c|c|c|c|c|c|c|}
\hline \multicolumn{8}{|c|}{ Panel A-Price momentum } \\
\hline momr & Ret & CFret & DRret & Eret & $R$ & Gr & SUE \\
\hline 1 & -7.186 & -4.333 & -3.835 & 0.983 & 0.132 & 0.199 & -1.065 \\
\hline 2 & -3.171 & -2.275 & -1.808 & 0.912 & 0.119 & 0.171 & -0.288 \\
\hline 3 & -1.468 & -1.468 & -0.880 & 0.880 & 0.113 & 0.159 & -0.045 \\
\hline 4 & -0.248 & -1.006 & -0.105 & 0.862 & 0.110 & 0.151 & 0.131 \\
\hline 5 & 0.799 & -0.708 & 0.657 & 0.850 & 0.108 & 0.148 & 0.313 \\
\hline 6 & 1.758 & -0.381 & 1.300 & 0.839 & 0.105 & 0.147 & 0.476 \\
\hline 7 & 2.784 & -0.051 & 2.003 & 0.832 & 0.104 & 0.150 & 0.558 \\
\hline 8 & 3.975 & 0.293 & 2.854 & 0.828 & 0.102 & 0.158 & 0.665 \\
\hline 9 & 5.703 & 0.802 & 4.078 & 0.824 & 0.101 & 0.172 & 0.802 \\
\hline 10 & 10.053 & 2.078 & 7.154 & 0.821 & 0.098 & 0.201 & 0.973 \\
\hline $10-1$ & 17.239 & 6.411 & 10.989 & -0.162 & -0.034 & 0.002 & 2.038 \\
\hline $\mathrm{t}$ & $(28.66)$ & $(31.56)$ & $(20.87)$ & $(-12.22)$ & $(-13.75)$ & $(0.43)$ & $(23.11)$ \\
\hline \multicolumn{8}{|c|}{ Panel B-Earnings momentum } \\
\hline momr & Ret & CFret & DRret & Eret & $R$ & $G r$ & SUE \\
\hline 1 & -0.998 & -2.877 & 0.977 & 0.902 & 0.115 & 0.157 & -4.749 \\
\hline 2 & -0.136 & -2.208 & 1.183 & 0.889 & 0.113 & 0.151 & -0.968 \\
\hline 3 & 0.347 & -1.702 & 1.166 & 0.882 & 0.112 & 0.149 & -0.379 \\
\hline 4 & 0.923 & -1.070 & 1.119 & 0.875 & 0.111 & 0.152 & -0.073 \\
\hline 5 & 1.501 & -0.423 & 1.059 & 0.864 & 0.109 & 0.156 & 0.133 \\
\hline 6 & 1.852 & -0.161 & 1.158 & 0.855 & 0.108 & 0.159 & 0.362 \\
\hline 7 & 2.120 & 0.122 & 1.152 & 0.846 & 0.107 & 0.165 & 0.681 \\
\hline 8 & 2.324 & 0.314 & 1.167 & 0.843 & 0.106 & 0.168 & 1.159 \\
\hline 9 & 2.514 & 0.508 & 1.175 & 0.832 & 0.105 & 0.177 & 1.944 \\
\hline 10 & 2.881 & 0.970 & 1.113 & 0.798 & 0.100 & 0.192 & 4.476 \\
\hline 10-1 & 3.879 & 3.847 & 0.136 & -0.104 & -0.014 & 0.035 & 9.225 \\
\hline $\mathrm{t}$ & $(25.62)$ & (30.61) & $(0.81)$ & $(-14.75)$ & $(-14.07)$ & (15.28) & (36.29) \\
\hline
\end{tabular}




\section{Table 6. Momentum profits for different holding horizons}

Panel A of this table presents the monthly profits of price momentum portfolios (D10-D1) with different holding periods. Panel B presents the monthly profits of earnings momentum. Equal-weighted monthly returns are reported. For example, Momentum13-18 refers to the strategy of forming a long-short portfolio based on past six-month returns and holding the portfolio from month 13 to month 18. Ret, CFret, DRret, and Eret represent the monthly total momentum return and the three decomposed monthly return components related to cash flows, discount rates, and expected returns, respectively. The sample period is from 1985 to 2008. All returns are in percentage. The $t$ statistics are in parentheses.

\begin{tabular}{lrrrrrrrr}
\hline Panel A-Price momentum & \multicolumn{1}{l}{ Ret } & t-statistic & CFret & t-statistic & DRret & t-statistic & Eret & t-statistic \\
\hline Strategy/D10-D1 & 0.8543 & $(2.85)$ & 4.9022 & $(27.15)$ & -3.9020 & $(-11.77)$ & -0.1459 & $(-6.43)$ \\
\hline Momentum1-6 & 0.2802 & $(1.18)$ & 1.6456 & $(12.06)$ & -1.2968 & $(-5.03)$ & -0.0687 & $(-3.80)$ \\
Momentum7-12 & -0.6883 & $(-3.17)$ & -0.1469 & $(-1.03)$ & -0.5116 & $(-2.07)$ & -0.0298 & $(-2.53)$ \\
Momentum13-18 & 0.0681 & $(0.34)$ & -0.1371 & $(-1.01)$ & 0.2306 & $(0.96)$ & -0.0254 & $(-2.22)$ \\
Momentum19-24 & -0.2254 & $(-1.52)$ & -0.2649 & $(-2.96)$ & 0.0654 & $(0.38)$ & -0.0259 & $(-2.28)$ \\
Momentum25-36 & & & & & & & &
\end{tabular}

\begin{tabular}{lrrrrrrrr}
\hline Panel B-Earnings momentum & \multicolumn{1}{l}{ Ret } & t-statistic & CFret & t-statistic & DRret & t-statistic & Eret & t-statistic \\
\hline Strategy/D10-D1 & 0.4235 & $(2.99)$ & 1.7706 & $(16.02)$ & -1.2680 & $(-6.93)$ & -0.0791 & $(-8.86)$ \\
\hline Momentum6-6 & 0.1406 & $(1.07)$ & 0.5441 & $(5.28)$ & -0.3416 & $(-1.99)$ & -0.0619 & $(-7.45)$ \\
Momentum7-12 & 0.1202 & $(0.87)$ & 0.3775 & $(3.83)$ & -0.2047 & $(-1.18)$ & -0.0526 & $(-7.82)$ \\
Momentum13-18 & -0.0222 & $(-0.19)$ & 0.1185 & $(1.30)$ & -0.0933 & $(-0.67)$ & -0.0474 & $(-7.23)$ \\
Momentum19-24 & -0.1286 & $(-1.16)$ & -0.1277 & $(-1.31)$ & 0.0476 & $(0.32)$ & -0.0485 & $(-7.44)$ \\
Momentum25-36 & & & & & & & &
\end{tabular}




\section{Table 7. Price momentum and information uncertainty}

This table presents average monthly portfolio returns and decomposed return components sorted by information uncertainty and price momentum. SIGMA is the standard deviation of weekly market excess returns over the past one year ending at the end of formation month (month $t$ ). Each month, all stocks are sorted into five groups (U1 to U5) based on their SIGMA and are then further sorted into five quintiles (M1 to M5) based on their past returns from month $t-6$ to month $t-1$. U1 (U5) denotes the lowest (highest) information uncertainty quintile. M1 (M5) denotes the lowest (highest) momentum quintile. All portfolios are held for six months and portfolio returns are equally weighted. All returns are in percentage. The $t$-statistics for the differences in returns between the two extreme quintile portfolios are reported in parentheses. The sample period is from 1985 to 2008.

\begin{tabular}{|c|c|c|c|c|c|c|c|c|}
\hline \multirow[b]{2}{*}{ Uncertainty } & \multicolumn{8}{|c|}{ Price momentum } \\
\hline & & M1 & $\mathrm{M} 2$ & $\mathrm{M} 3$ & M4 & M5 & M5-M1 & t-statistic \\
\hline U1 & Ret & 1.1508 & 1.1365 & 1.0602 & 0.9640 & 1.0387 & -0.1121 & $(-0.73)$ \\
\hline U2 & & 0.9777 & 1.0570 & 1.0775 & 1.0935 & 1.2181 & 0.2405 & $(1.36)$ \\
\hline U3 & & 0.8976 & 0.9275 & 1.1120 & 1.1394 & 1.5174 & 0.6198 & (2.73) \\
\hline U4 & & 0.8202 & 0.9120 & 1.1874 & 1.2207 & 1.6160 & 0.7958 & (2.89) \\
\hline U5 & & 0.5173 & 0.7696 & 0.9701 & 1.2046 & 1.6822 & 1.1649 & (3.83) \\
\hline U5-U1 & & -0.6335 & -0.3669 & -0.0902 & 0.2406 & 0.6435 & 1.2770 & (4.79) \\
\hline t-statistic & & $(-1.52)$ & $(-0.91)$ & $(-0.24)$ & $(0.64)$ & (1.63) & (4.79) & \\
\hline U1 & CFret & -1.1120 & -0.5470 & -0.2529 & -0.0787 & 0.4060 & 1.5184 & (12.65) \\
\hline U2 & & -1.7860 & -0.9523 & -0.4492 & 0.0195 & 0.6897 & 2.4754 & (17.74) \\
\hline U3 & & -2.5340 & -1.3470 & -0.6989 & -0.0608 & 0.9492 & 3.4829 & (20.25) \\
\hline U4 & & -3.2000 & -1.7960 & -0.8026 & -0.0835 & 1.1489 & 4.3484 & $(22.60)$ \\
\hline U5 & & -4.2550 & -2.5110 & -1.5170 & -0.5244 & 1.0056 & 5.2608 & (22.67) \\
\hline U5-U1 & & -3.1430 & -1.9640 & -1.2640 & -0.4457 & 0.5997 & 3.7424 & (15.34) \\
\hline t-statistic & & $(-16.63)$ & $(-13.97)$ & $(-9.60)$ & $(-3.20)$ & (3.55) & (15.34) & \\
\hline U1 & DRret & 1.4322 & 0.8766 & 0.5193 & 0.2564 & -0.1431 & -1.5750 & $(-7.57)$ \\
\hline U2 & & 1.8875 & 1.1579 & 0.6912 & 0.2552 & -0.2669 & -2.1540 & $(-9.89)$ \\
\hline U3 & & 2.5192 & 1.3921 & 0.9512 & 0.3647 & -0.2439 & -2.7630 & $(-10.00)$ \\
\hline U4 & & 3.0722 & 1.7966 & 1.1051 & 0.4443 & -0.3517 & -3.4240 & $(-10.66)$ \\
\hline U5 & & 3.7721 & 2.3296 & 1.5678 & 0.8397 & -0.1793 & -3.9510 & $(-10.95)$ \\
\hline U5-U1 & & 2.3399 & 1.4530 & 1.0485 & 0.5833 & -0.0362 & -2.3760 & $(-6.9)$ \\
\hline t-statistic & & $(5.47)$ & (3.44) & $(2.76)$ & $(1.56)$ & $(-0.09)$ & $(-6.9)$ & \\
\hline U1 & Eret & 0.8311 & 0.8069 & 0.7939 & 0.7863 & 0.7758 & -0.0553 & $(-4.14)$ \\
\hline U2 & & 0.8759 & 0.8515 & 0.8355 & 0.8188 & 0.7953 & -0.0806 & $(-5.40)$ \\
\hline U3 & & 0.9121 & 0.8826 & 0.8597 & 0.8355 & 0.8121 & -0.1000 & $(-5.57)$ \\
\hline U4 & & 0.9476 & 0.9113 & 0.8850 & 0.8599 & 0.8189 & -0.1287 & $(-6.19)$ \\
\hline U5 & & 1.0004 & 0.9508 & 0.9194 & 0.8894 & 0.8558 & -0.1445 & $(-6.22)$ \\
\hline U5-U1 & & 0.1693 & 0.1439 & 0.1255 & 0.1031 & 0.0800 & -0.0892 & $(-6.26)$ \\
\hline t-statistic & & (10.54) & $(8.82)$ & (7.43) & (7.09) & $(6.00)$ & $(-6.26)$ & \\
\hline
\end{tabular}




\section{Table 8. Earnings momentum and information uncertainty}

This table presents average monthly portfolio returns and decomposed return components sorted by earnings momentum and information uncertainty. SIGMA is the standard deviation of weekly market excess returns over the past one year ending at the end of formation month (month $t$ ). Each month, all stocks are sorted into five groups (U1 to U5) based on their SIGMA and are further sorted into five quintiles (M1 to M5) based on their SUE. U1 (U5) denotes the lowest (highest) information uncertainty quintile. M1 (M5) denotes the lowest (highest) momentum quintile. All portfolios are held for six month and portfolio returns are equally weighted. All returns are in percentage. The $t$-statistics for the differences in returns between extreme quintile portfolios are reported in parentheses. The sample period is from 1985 to 2008.

\begin{tabular}{|c|c|c|c|c|c|c|c|c|}
\hline \multirow[b]{2}{*}{ Uncertainty } & \multicolumn{8}{|c|}{ Earnings momentum } \\
\hline & & M1 & M2 & M3 & M4 & M5 & M5-M1 & t-statistic \\
\hline $\mathrm{U} 1$ & Ret & 0.9598 & 0.9926 & 1.0538 & 1.1288 & 1.1799 & 0.2200 & $(2.21)$ \\
\hline U2 & & 0.9537 & 1.0795 & 1.0636 & 1.0431 & 1.2280 & 0.2743 & (2.37) \\
\hline U3 & & 0.8381 & 1.0587 & 1.1196 & 1.2087 & 1.2873 & 0.4492 & $(2.90)$ \\
\hline U4 & & 0.8008 & 1.0674 & 1.2318 & 1.2909 & 1.3310 & 0.5302 & (3.04) \\
\hline U5 & & 0.5510 & 1.0213 & 1.0899 & 1.3295 & 1.2647 & 0.7137 & (3.41) \\
\hline U5-U1 & & -0.4089 & 0.0287 & 0.0361 & 0.2007 & 0.0848 & 0.4937 & (2.41) \\
\hline t-statistic & & $(-1.04)$ & $(0.07)$ & (0.09) & $(0.50)$ & $(0.21)$ & $(2.41)$ & \\
\hline U1 & CFret & -0.5825 & -0.5796 & -0.4007 & -0.0944 & -0.0036 & 0.5789 & (5.13) \\
\hline U2 & & -1.0740 & -0.8265 & -0.4885 & -0.2332 & 0.1201 & 1.1943 & (10.05) \\
\hline U3 & & -1.4100 & -1.1610 & -0.6741 & -0.3129 & 0.0011 & 1.4114 & $(9.75)$ \\
\hline U4 & & -1.9390 & -1.3690 & -0.8614 & -0.4820 & -0.1489 & 1.7903 & (11.34) \\
\hline U5 & & -2.7240 & -2.0740 & -1.3730 & -1.0010 & -0.6623 & 2.0617 & (10.12) \\
\hline U5-U1 & & -2.1410 & -1.4950 & -0.9728 & -0.9065 & -0.6587 & 1.4827 & $(6.56)$ \\
\hline t-statistic & & $(-12.19)$ & $(-9.27)$ & $(-6.02)$ & $(-5.57)$ & $(-3.70)$ & $(6.56)$ & \\
\hline U1 & DRret & 0.7289 & 0.7621 & 0.6537 & 0.4318 & 0.4099 & -0.3190 & $(-2.04)$ \\
\hline U2 & & 1.1747 & 1.0581 & 0.7120 & 0.4476 & 0.3111 & -0.8635 & $(-5.28)$ \\
\hline U3 & & 1.3691 & 1.3437 & 0.9350 & 0.6734 & 0.4665 & -0.9026 & $(-4.37)$ \\
\hline U4 & & 1.8330 & 1.5384 & 1.2101 & 0.9081 & 0.6399 & -1.1930 & $(-5.05)$ \\
\hline U5 & & 2.3456 & 2.1749 & 1.5386 & 1.4183 & 1.0384 & -1.3070 & $(-4.60)$ \\
\hline U5-U1 & & 1.6167 & 1.4127 & 0.8849 & 0.9865 & 0.6285 & -0.9882 & $(-3.44)$ \\
\hline t-statistic & & (3.85) & $(3.55)$ & $(2.27)$ & $(2.42)$ & $(1.52)$ & $(-3.44)$ & \\
\hline U1 & Eret & 0.8135 & 0.8101 & 0.8009 & 0.7914 & 0.7735 & -0.0399 & $(-5.66)$ \\
\hline U2 & & 0.8532 & 0.8479 & 0.8401 & 0.8287 & 0.7968 & -0.0564 & $(-9.29)$ \\
\hline U3 & & 0.8793 & 0.8762 & 0.8586 & 0.8481 & 0.8196 & -0.0597 & $(-6.77)$ \\
\hline U4 & & 0.9071 & 0.8979 & 0.8831 & 0.8648 & 0.8400 & -0.0671 & $(-5.27)$ \\
\hline U5 & & 0.9293 & 0.9207 & 0.9248 & 0.9121 & 0.8886 & -0.0407 & $(-3.74)$ \\
\hline U5-U1 & & 0.1158 & 0.1106 & 0.1239 & 0.1207 & 0.1150 & -0.0008 & $(-0.08)$ \\
\hline t-statistic & & $(7.82)$ & $(6.40)$ & (8.49) & (7.74) & $(8.53)$ & $(-0.08)$ & \\
\hline
\end{tabular}




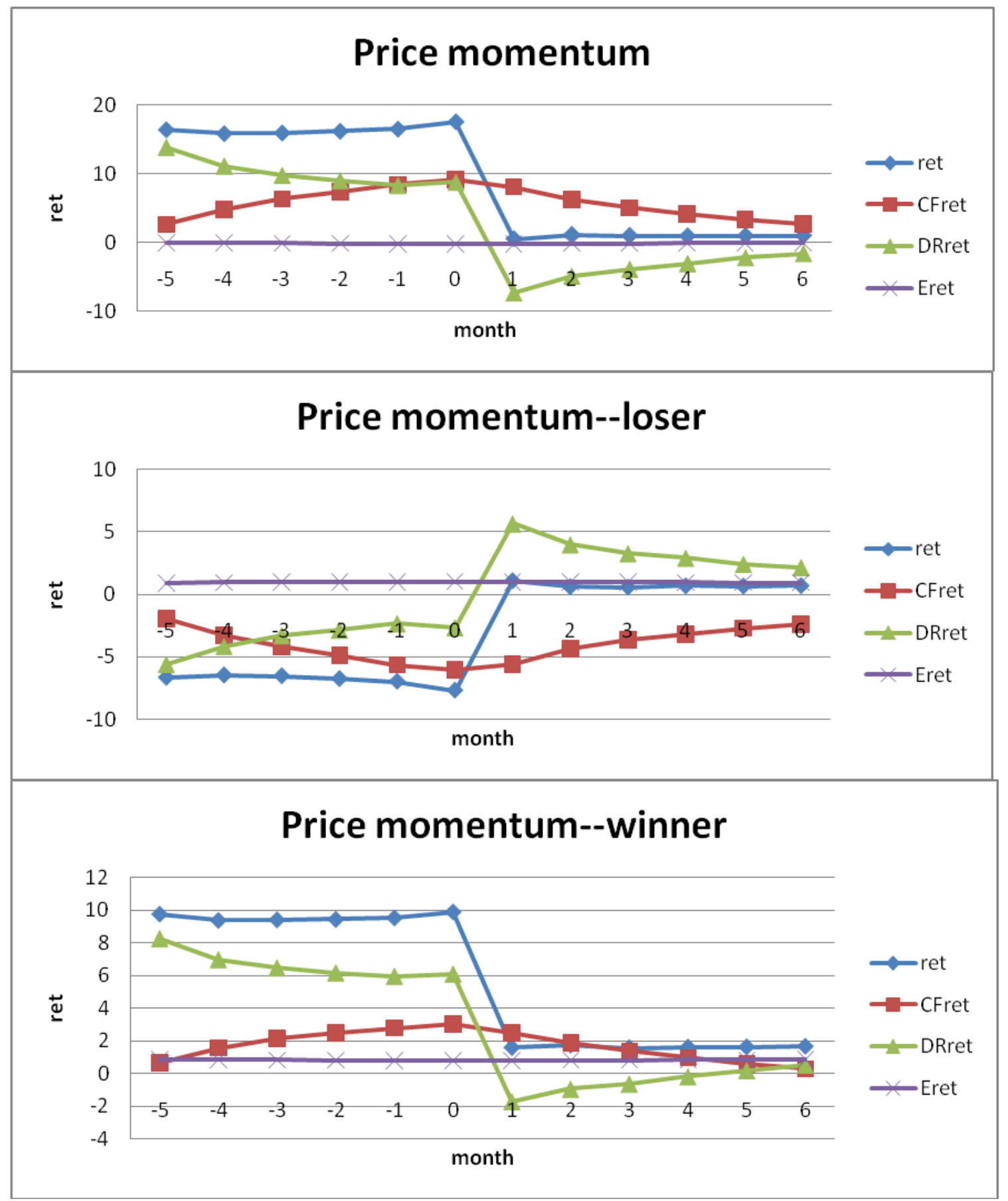

Figure 1. Decomposed return components of price momentum portfolios during pre- and post-formation periods. The figures present month-by-month decomposed return components (the realized return, expected return, cash flow return, and discount rate return) for the hedge portfolio (winners minus losers), the loser portfolio and the winner portfolio from a price momentum strategy six months before and six months after portfolio formation. These figures display the results tabulated in Table 3. 


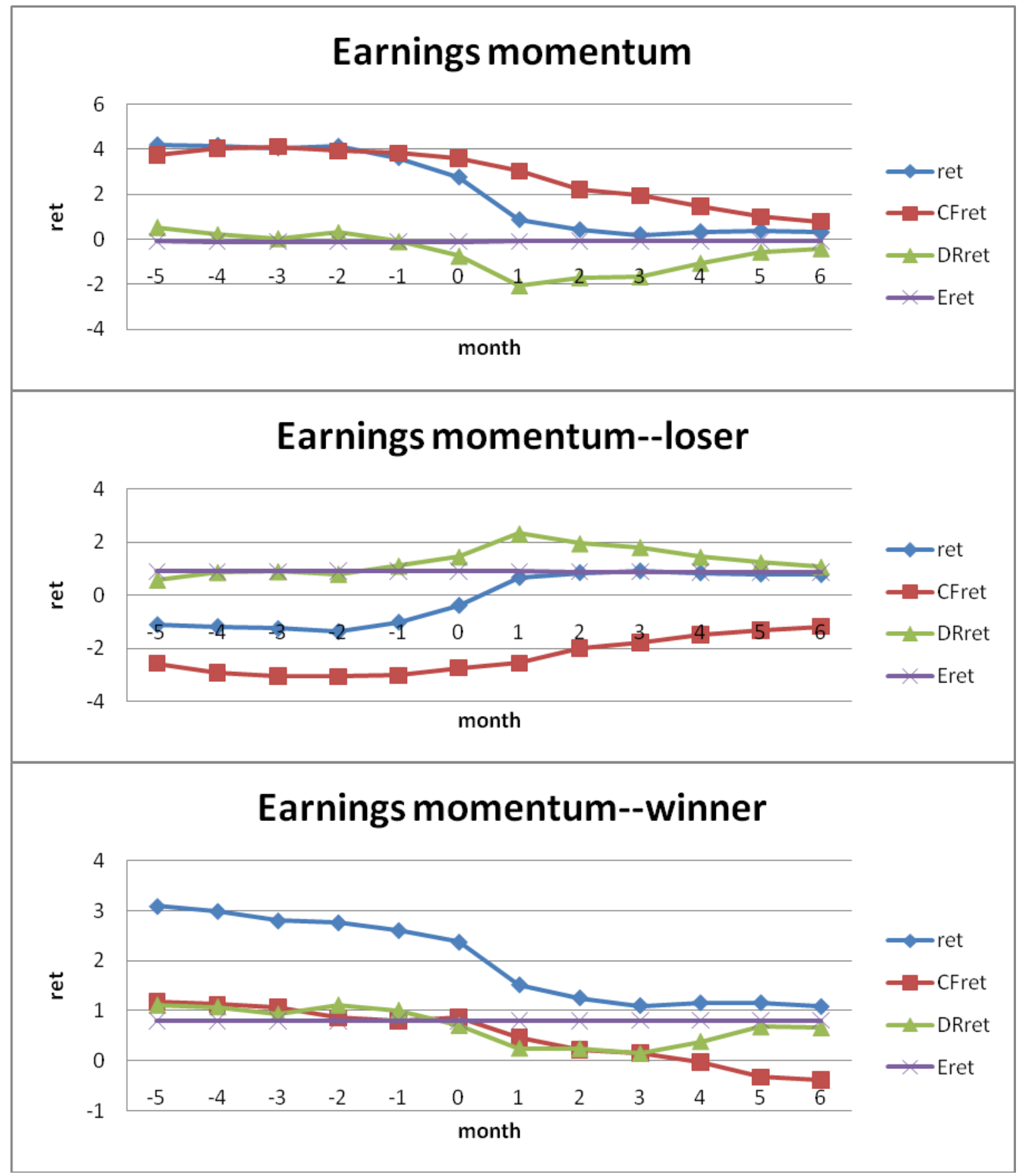

Figure 2. Decomposed return components of earnings momentum portfolios during pre- and post-formation periods. The figures present month-by-month decomposed return components (the realized return, expected return, cash flow return, and discount rate return) for the hedge portfolio (winners minus losers), the loser portfolio and the winner portfolio from a earnings momentum strategy six months before and six months after portfolio formation. These figures display the results tabulated in Table 4. 


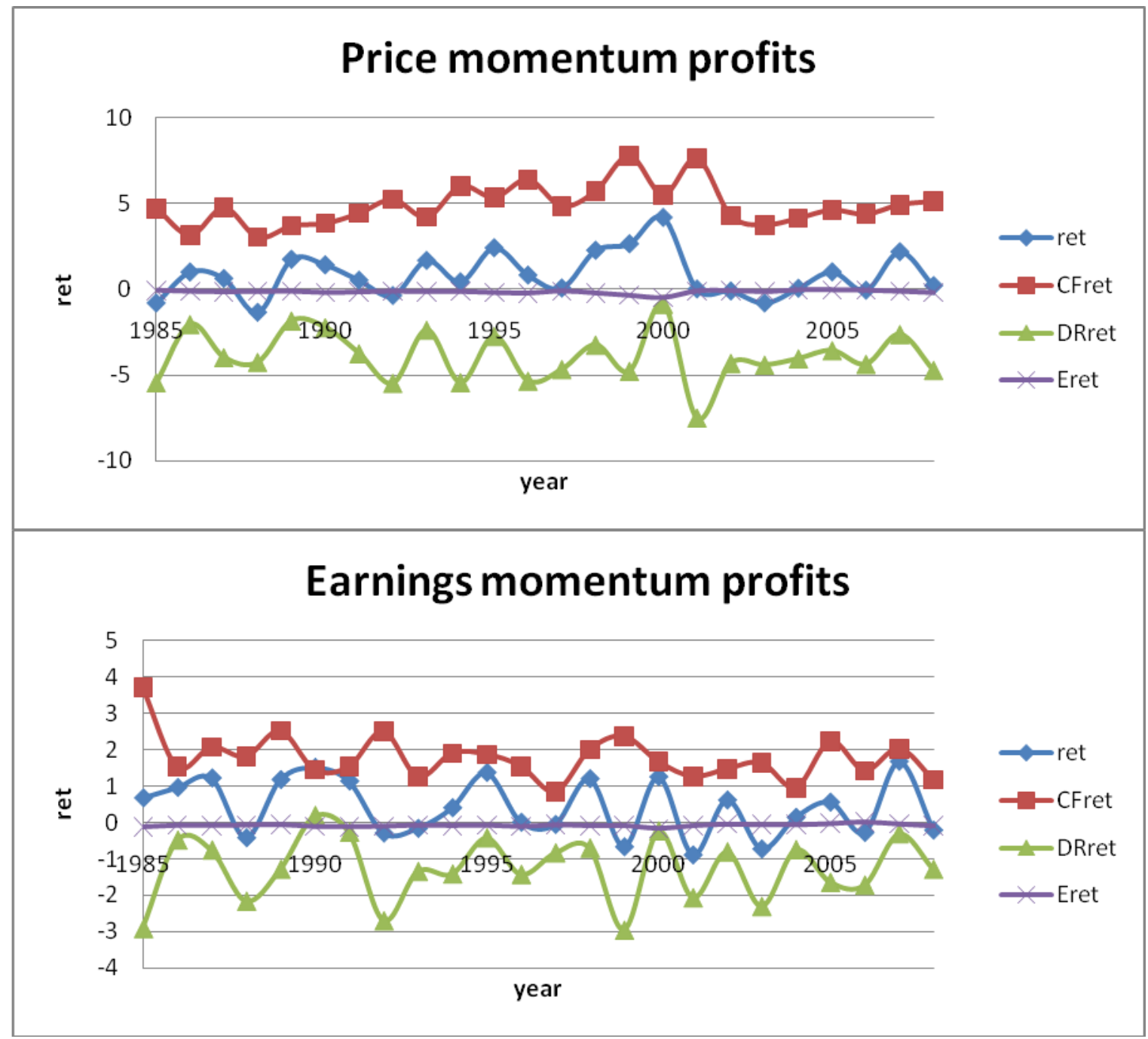

Figure 3. Calendar-time properties of momentum profits. The figures present calendar-time momentum profits for price momentum and earnings momentum portfolio from 1985 to 2008. The monthly total return, expected return component, cash flow return component and discount rate return component (in percentage) are presented separately. 